\title{
PERDA DE SOLO POR EROSÃO HÍDRICA EM BACIA HIDROGRÁFICA: O CASO DA ÁREA DE DRENAGEM DA BARRAGEM DO RIO JURAMENTO, NO NORTE DO ESTADO DE MINAS GERAIS
}

\author{
Willer Fagundes Oliveira \\ Professor Mestre do Departamento de Ciências Agrárias da Unimontes \\ willerengenharia@hotmail.com \\ Marcos Esdras Leite \\ Professor Doutor do Departamento de Geociências Unimontes \\ marcos.leite@unimontes.br
}

\begin{abstract}
RESUMO
A erosão hídrica é um dos mais importantes problemas de degradação do solo. A identificação de áreas com problemas de erosão hídrica faz se necessária para propor técnicas conservacionistas que mitigam tal fenômeno. O levantamento de informações inerentes ao processo erosivo hídrico pode ser realizado por meio de diversas ferramentas, em especial por meio das geotecnológicas livres, como software, imagens de satélite e de radar. Analisar a erosão em bacias hidrográficas com presença de barragem para abastecimento humano é importante para monitorar a capacidade de armazenamento de água nesse reservatório. Diante dessa situação, a área deste estudo é a Área de Drenagem da Barragem do Rio Juramento (ADBRJ), representa 98,3\% da bacia hidrográfica do Rio Juramento, sendo responsável por $67 \%$ no abastecimento de água na cidade de Montes Claros. Nesse contexto, este trabalho tem como principal objetivo identificar as áreas de Risco de Erosão Laminar (REL) por meio de ferramentas geotecnológicas livres. De maneira específica, buscou-se estimar a perda de solos por meio da Universal Soil Loss Equation (USLE) para o ano 2015. Os resultados apontam que o risco de erosão laminar aumenta, significativamente, quando as práticas conservacionistas são desconsideradas. Cerca de $52 \%$ da área total da bacia, encontra-se entre Muito Baixo e Baixo Risco de Erosão laminar. Entretanto, 32,91\% estão com Alto a Muito Alto Risco de Erosão Laminar. Constatou com a aplicação da USLE que na área de estudo perde-se, em média, 48,01 t.ha ${ }^{-1}$.ano ${ }^{-1}$, valores que a classifica como magnitude média em perdas de solos por erosão laminar.
\end{abstract}

Palavras-chave: Degradação. Solo. Geotecnologias.

\section{SOIL LOSS BY WATER EROSION IN HYDROGRAPHIC BASIN: THE CASE OF THE DRAINAGE AREA OF THE JURAMENTO RIVER BARRAGE, IN THE NORTH OF THE STATE OF MINAS GERAIS}

\begin{abstract}
Water erosion is one of the most important land degradation problems. The identification of areas with problems of water erosion makes it necessary to propose conservation techniques that mitigate this phenomenon. The collection of information inherent to the erosive water process can be done by means of several tools, in particular through the free geotechnology such as software, satellite image and radar. Analyzing erosion in watersheds with presence of dam for human supply is important to monitor the storage capacity of water in this reservoir. Given this situation, the area of this study is the Drainage Area of the Juramento River Dam (ADBRJ), representing 98,3\% of the Juramento river basin, accounting for $67 \%$ of the water supply in the city of Montes Claros. In this context, this work has as main objective, to identify the areas of Laminar Erosion Risk (REL) through free geotechnological tools. Specifically, we attempted to estimate soil loss through the Universal Soil Loss Equation (USLE) for the year 2015. The results indicate that the risk of laminar erosion increases significantly when conservation practices are disregarded. About $52 \%$ of the total area of the basin is between Very Low and Low Risk of Laminar Erosion. However,
\end{abstract}


$32.91 \%$ are with High to Very High Laminar Erosion Risk. It was verified by the application of USLE that in the study area it loses, on average, 48.01 t.ha $^{-1}$.ano- ${ }^{-1}$, values that classify it as average magnitude in soil losses by laminar erosion.

Keywords: Degradation. Soil. Geotechnology.

\section{INTRODUÇÃO}

O solo é um recurso natural e essencial para a manutenção dos diversos ecossistemas terrestres. A degradação desse valioso recurso já é uma preocupação global. Há uma necessidade crescente de se manejar esses recursos eficientemente, numa base sustentável, sendo essa tarefa, uma responsabilidade de todos (IBGE, 2015). A erosão hídrica é um dos mais importantes problemas de degradação do solo no mundo em tempos correntes, sendo considerada um risco de preocupação significativa (DEVATHA; DESHPANDE; RENUKAPRASAD, 2015).

Estudos apontam que $33 \%$ dos solos do mundo estão degradados(FAO, 2015). Entre os principais problemas, estão os relacionados à erosão, salinização, compactação, acidificação e contaminação. Isso, possivelmente, trará alguns prejuízos, tais como: perda de fertilidade do solo, perda na produção e produtividade agropecuária, aumento no custo de produção, avanços das fronteiras agrícolas, desflorestamento, ineficiência na captação de carbono da atmosfera, volatilidade dos preços dos alimentos, assoreamento dos rios, intensificação de enchentes e principalmente, o mais agravante, a escassez hídrica.

Neste contexto, a gestão de bacia hidrográfica merece atenção, por se tornar um recorte espacial de interesse da geografia. É neste espaço, que o relevo transforma-se ao longo do tempo, devido ao processo erosivo que ocorre de maneira natural e, em alguns momentos, de maneira intensificada pelo uso inadequado do solo.

Para Rosa (2011) a complexidade do espaço geográfico pode ser compreendida a partir da fragmentação do mesmo, sendo o Sistema de Informação Geográfica relevante neste processo. A quantificação tem como mérito, enriquecer a geografia com o uso de modelos matemáticos e estatísticos nas análises e na busca de aprimoramento metodológico. Neste sentido, as ferramentas geotecnológicas oferecem oportunidades inovadoras que geram novos desafios (COSTA; ROCHA, 2010).

Objetivando mapear e analisar a susceptibilidade erosiva do solo no Município de Paraíso das Águas - MS, no ano de 2013, Barbosa et al.( 2015) utilizaram a USLE em softwares livres (QGIS, gvSIG e LS-TOOLS) e conseguiram estimar as perdas médias anuais de solo (variando de 0 a 1.307,32 t.ha ${ }^{1}$.ano-1 ) para o referido município. Os mesmos autores afirmam que a utilização de softwares livres foi satisfatória e adequada aos propósitos do trabalho.

O manancial do Reservatório da Barragem do Rio Juramento ou Área de Drenagem da Barragem do Rio Juramento (ADBRJ) é responsável por $67 \%$ no abastecimento de água da cidade de Montes Claros (ANA, 2010). Tal reservatório possui potencial hídrico para abastecer no máximo 500.000 habitantes (COPASA, 1983). Entretanto, estudos realizados pela Companhia de Saneamento de Minas Gerais (COPASA) afirmavam que a disponibilidade hídrica da bacia do Rio Verde Grande, onde se localiza a ADBRJ, está comprometida, impossibilitando a expansão do abastecimento público para suprir novas demandas (ANA, 2013).

Sendo assim, este trabalho teve como principal objetivo, analisar as áreas de risco de erosão hídrica laminar na ADBRJ, por meio de ferramentas geotecnológicas livres. De maneira específica, buscouse estimar as perdas de solo usando a Universal Soil Loss Equation (USLE) para o ano 2015.

\section{ÁREA DE ESTUDO}

A ADBRJ está localizada na bacia do Rio Verde Grande, afluente do Rio São Francisco, mesorregião Norte de Minas, Estado de Minas Gerais, especificamente na microrregião de Montes Claros. O limite da referida área compreende um retângulo envolvente entre as coordenadas Planas UTM: $\mathrm{E}=641.911, \mathrm{~N}=8.123 .210$; $\mathrm{E}=666.719, \mathrm{~N}=8.148 .631$; fuso $23 \mathrm{k}$ e Sistema de Referência (Datum) SIRGAS 2000. A área encontra-se inserida, totalmente, no município de Juramento, confrontando

$\begin{array}{llllll}\text { Caminhos de Geografia } & \text { Uberlândia - MG } & \text { v. 19, n.67 } & \text { Set/2018 } & \text { p. 16-37 } & \text { Página } 17\end{array}$


com os municípios de Francisco Sá, Grão Mogol, Itacambira, Guaraciama e Glaucilândia (Figura 1). Ressalta-se que o polígono da área de estudo corresponde a $81,63 \%$ da área total do município de Juramento, perfazendo uma área de 35.695,12 ha.

Figura 1: Localização da ADBRJ.

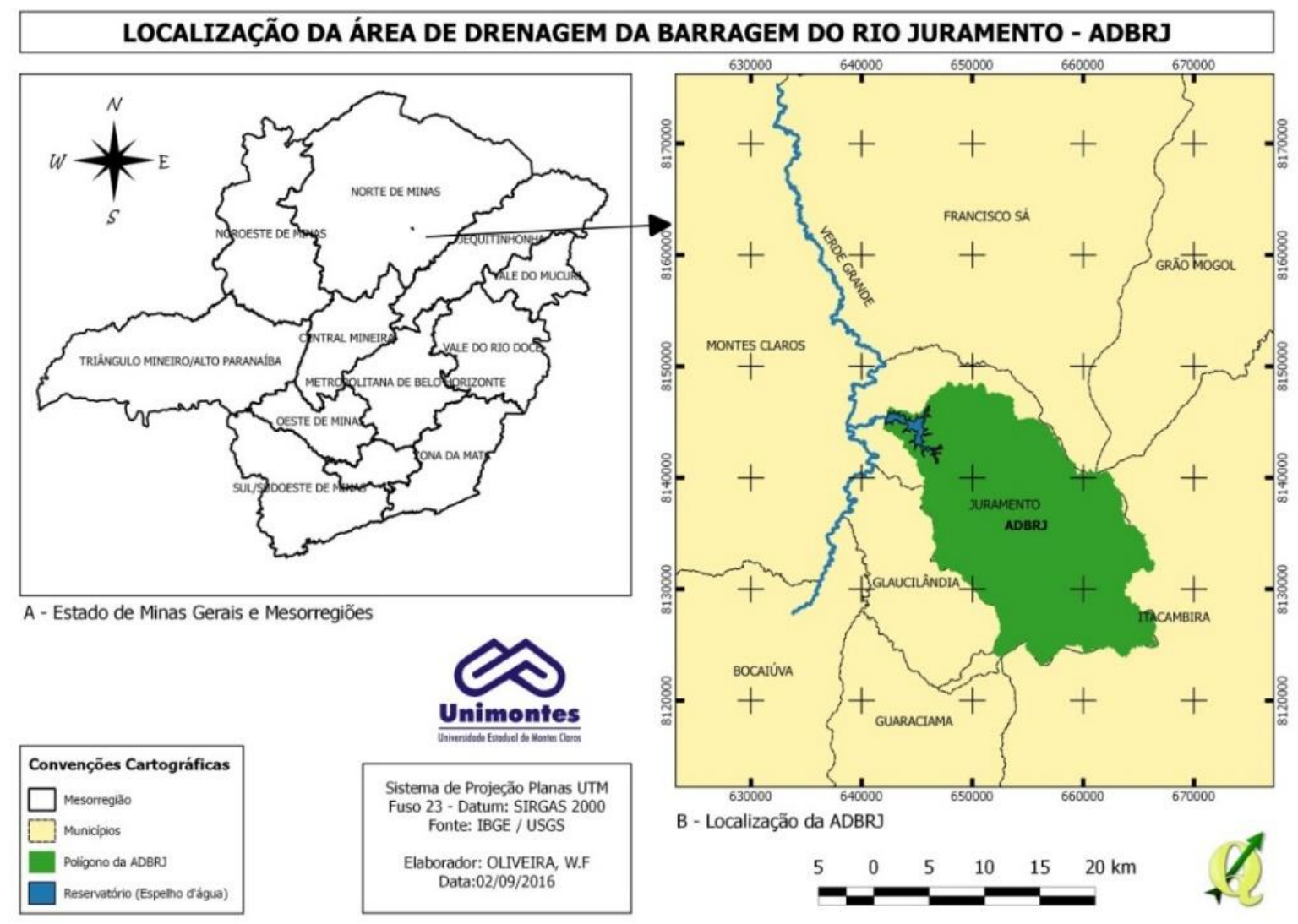

O bioma característico é do tipo Cerrado, onde as fitofisionomias ocorrentes na referida área são: Campo, Campo Cerrado, Cerrado Senso Stricto, Floresta Estacional Semidecidual e Floresta Estacional Decidual (SIAM, 2016). As referidas fitofisionomias, juntamente com as Pastagens e a Silvicultura (Eucalipto), compõem a cobertura vegetal da ADBRJ. A precipitação média anual é de $982,5 \mathrm{~mm}$, com clima do tipo C1 s A' a', ou seja, Subúmido Seco com excesso de água moderado no verão(OLIVEIRA, 2017).

\section{METODOLOGIA}

O Modelo Digital da Superfície (MDS) utilizado para determinar o limite da ADBRJ foi o MDS-RTC ALPSRP076726840 (Path 81, Frame 6840), resolução espacial de 12,5 x 12,5m, obtido por meio do portal interativo de Banco de Dados Geográficos da Alaska Satellite Facility (ASF) referido MDS, Radiometrically Terrain-Corrected (RTC), é produto de uma correção do MDS SRTM GL1,o qual apresenta uma série de anomalias e, portanto, para algumas aplicações, faz-se necessário a eliminação de tais dados espúrios. Uma vez selecionado o MDS, a próxima etapa consistiu na delimitação automática da área a montante do exutório considerado, que neste caso, o limiar definido foi o vertedouro da Barragem do Rio Juramento. Nesse procedimento, utilizou-se o software MapWindow Open Source (4.8.8) por meio do pluginWathershed delineation.

Após a delimitação da área a montante do exutório (Vertedouro da Barragem do Rio Juramento), foi possível determinar a área de drenagem por meio da fórmula (1).

$\begin{array}{llllll}\text { Caminhos de Geografia } & \text { Uberlândia - MG } & \text { v. 19, n. } 67 & \text { Set/2018 } & \text { p. 16-37 } & \text { Página } 18\end{array}$


$A d=A m-A r-A u$

Em que (Ad) é a área de contribuição ou ADBRJ, (Am) é a área a montante do exutório e (Ar) área do reservatório (espelho d'água) na cota máxima $(646,30 \mathrm{~m})$, ou seja, 476,22 ha. Já (Au) é a área urbanizada (Cidade / Distrito),109,84 ha.

A estimativa das perdas de solo por erosão laminar foi realizada por meio da Universal Soil Loss Equation (USLE), publicada em 1965 por Wischmeier e Smith, USDA Agriculture Handbook 282, atualizada 13 anos mais tarde, Agriculture Handbook 537, também publicada pelos pesquisadores Wischmeier e Smith.

A partir da integração de algumas variáveis consideradas relevantes no processo erosivo (a chuva, o solo, o relevo, a cobertura do solo e as práticas conservacionistas) a USLE fornece a estimativa média da perda anual de solo, de acordo com a fórmula 2.

$A=$ R.K.LS.C.P (2)

Onde:

A é a perda de solo por erosão laminar (PSEL), em (t.ha $\left.{ }^{-1} \cdot \mathrm{ano}^{-1}\right)$;

$\mathbf{R}$ é o Fator Erosividade (MJ.mm. ha ${ }^{-1} \cdot \mathrm{h}^{-1} \cdot \mathrm{ano}^{-1}$ );

K é o Fator Erodibilidade (t.h.MJ ${ }^{-1} \mathrm{~mm}^{-1}$ );

LS é o Fator Topográfico (Adimensional);

C é o Fator de Uso e Manejo (Adimensional);

P é a Prática Conservacionista (Adimensional).

A seguir, encontram-se os procedimentos adotados para determinar os inputs da fórmula (2).

\section{FATOR EROSIVIDADE (R)}

Foram utilizados dados diários das estações climatológicas oficiais (1643007, 1643038 e 1643019), disponíveis no Sistema de Informações Hidrológicas (HidroWeb 3.0) da Agência Nacional de Águas (ANA), bem como os dados de duas estações climatológicas (83452 e 83437), também oficiais, disponíveis no banco de dados meteorológicos do Centro de Estudos de Convivência com o Semiárido (CECS). Visando obter uma série histórica mensal e anual contínua, bem como um único banco de dados com valores representativos para a área de estudo, tornou-se necessário a realização de estudos de consistência, homogeneidade e preenchimento de falhas entre as estações supracitadas. Tal procedimento proporcionou obter valores de precipitação média mensal e anual com 51 anos de registros ininterruptos.

Como os valores de precipitação foram oriundos de pluviômetros, foi necessário obter o índice de Fournier Modificado (MFI), fórmula 3, pois tal índice depende apenas dos valores médios mensais e da média anual de precipitação.

$\mathrm{MFI}=\sum_{\mathrm{i}=1}^{12} \frac{\mathrm{p}_{\mathrm{i}}^{2}}{\mathrm{P}_{\mathrm{a}}}$

Onde MFI é o coeficiente da chuva $(\mathrm{mm}) ;\left(\mathrm{P}_{\mathrm{i}}\right)$ é a precipitação média de cada mês; $\left(\mathrm{P}_{\mathrm{a}}\right)$ é a precipitação média anual $(\mathrm{mm})$.

Em seguida, foi determinado o fator $\mathbf{R}\left(\mathrm{MJ} . \mathrm{mm} . \mathrm{ha}^{-1} \cdot \mathrm{h}^{-1} \cdot \mathrm{ano}^{-1}\right)$, conforme a fórmula4, proposta para o Norte de Minas Gerias por Da Silva (2004).

$\mathrm{R}=42,307 . \mathrm{MFI}+69,763$

\section{FATOR ERODIBILIDADE (K)}

A caracterização pedológica é peça imprescindível neste estudo, a qual a erosão é o principal fenômeno a ser investigado. Sendo assim, a partir do levantamento pedológico pré-existente (Mapa de Solos do Estado de Minas Gerais, elaborado por UFV et al. (2010), escala de 1:600.000 - Baixa Intensidade), confeccionou-se uma Carta Pedológica com unidades de solos (até ao $4^{\circ} \mathrm{Nível}$ do

\begin{tabular}{llllll}
\hline Caminhos de Geografia & Uberlândia - MG & v. 19, n. 67 & Set/2018 & p. 16-37 & Página 19
\end{tabular}


Sistema Brasileiro de Classificação de Solos proposto pela Embrapa (2013)) mais homogêneas e mais detalhadas, ou seja, aumentou-se a escala de mapeamento (1:100.000 - Alta Intensidade) (Figura 2).

Depois de estabelecida as unidades pedológicas existentes, foram coletadas, com trado holandês, amostras deformadas de solo, entre 10 a $20 \mathrm{~cm}$ de profundidade, totalizando 19 pontos amostrais, distribuídas aleatoriamente, em cada unidade pedológica. As amostras foram submetidas às seguintes análises laboratoriais físicas e químicas: granulométrica/textura (fração menor que $2 \mathrm{~mm}$ de diâmetro), pH em água, matéria orgânica. De posse dos valores percentuais de areia, silte e argila, realizou-se a classificação da textura do solo utilizando o triângulo textural disponível em USDA (2016).

Posteriormente, foi realizado o subfracionamento das partículas de areias $(2,0$ a $0,053 \mathrm{~mm})$ nas seguintes classes: muito grossa $(2,0$ a $1,0 \mathrm{~mm})$, grossa $(1,0$ a $0,5 \mathrm{~mm})$, média $(0,5$ a $0,250 \mathrm{~mm})$, fina $(0,250$ a $0,105 \mathrm{~mm})$ e muito fina $(0,105$ a $0,053 \mathrm{~mm})$.

Figura 2: Carta das Unidades Pedológicas da ADBRJ, Baixa e Alta Intensidade.

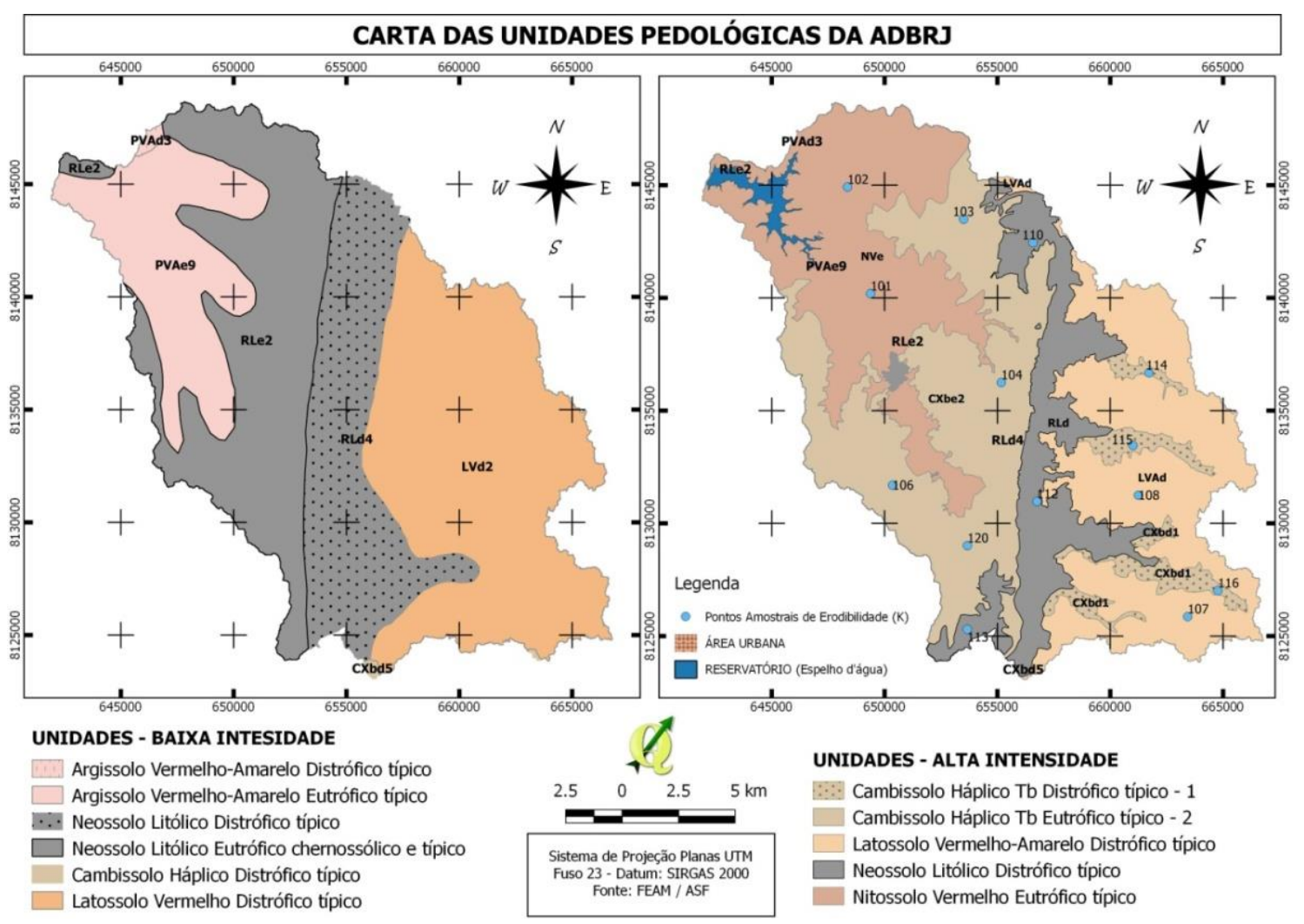

O fator K (t.h.MJ ${ }^{-1} \mathrm{~mm}^{-1}$ ) foi estimado por meio do método indireto proposto por Denardin (1990), fórmula(5).

$$
K=0,00000748 \text {. (M) + 0,00448059. (P) - 0,0631175. (DMP) + 0,01039567. (REL) }
$$

Onde:

$\mathbf{M}=(\%)$ Novo silte.[(\%)Novo silte + (\%)Nova areia)], em que Novo silte=Areia muito fina(\%) + Fração silte (\%) e Nova areia=Frações de areia com diâmetros entre 2,0 e 0,1 mm.

P é a permeabilidade do perfil de solo codificada conforme Wischmeier et al. (1971), apresentado no Quadro 1. 
Quadro 1: Valores de permeabilidade conforme as classes texturais do solo.

\begin{tabular}{|l|c|l|}
\hline \multicolumn{1}{|c|}{ Classe textural $^{\mathbf{1}}$} & Valores de permeabilidade $^{2}$ & \multicolumn{1}{|c|}{ Classe de permeabilidade $^{-1}$} \\
\hline Muito argilosa, Argilosa e Argilo-siltosa & 6 & Muito lenta \\
\hline Franco-argilo-siltosa e Argilo-arenosa & 5 & Lenta \\
\hline Franco-argilo-arenosa e Franco-argilosa & 3 & Lenta a moderada \\
\hline Franca, Franco-siltosa e Siltosa & 2 & Moderada \\
\hline Areia-franca e Franco-arenosa & 1 & Moderada a rápida \\
\hline Arenosa & Rápida \\
\hline
\end{tabular}

Fonte: (USDA, 2017) ${ }^{1}$; (WISCHMEIER;JOHNSON;CROSS, 1971 apud DEMARCHI e ZIMBACK, 2014) ${ }^{2}$

DMP é o diâmetro médio ponderado das partículas menores que $2 \mathrm{~mm}$, expresso em $\mathrm{mm}$, obtido por meio da fórmula (6) proposta por Arraes et al. (2010).

$\mathbf{D M P}=\frac{\mathbf{L}(0,65 . \text { Areia Grossa\% })+(0,15 . \text { Areia Fina\% })+(0,0117 . \text { Silte } \%)+(0,00024 . \text { Argila\% })]}{100}$

REL é o produto do teor de matéria orgânica (\%) pelo teor da "Nova Areia (\%)" obtida por meio da fórmula (7) apresentada por Denardin (1990).

$$
\text { REL }=\frac{\text { L(M.O\%).(Nova Areia\%)] }}{100}
$$

O fator $\mathbf{K}$ de cada Unidade Pedológica foi estimado para cada amostra e, logo em seguida, obteve-se um Fator Médio de Erodibilidade $(\overline{\boldsymbol{K}})$, cartografado em formato raster (.tif) com resolução espacial de $30 \times 30$ metros, para cada unidade pedológica da ADBRJ. Por fim, classificou-se cada unidade pedológica de acordo com os intervalos de $\overline{\mathbf{K}}\left(\mathrm{t} \cdot \mathrm{h} \cdot \mathrm{MJ}^{-1} \cdot \mathrm{mm}^{-1}\right)$ propostos por Arraes, Bueno e Pissara (2010): muito baixa $(<0,010)$, baixa $(0,010$ a 0,020$)$, moderada $(0,020$ a 0,030$)$, alto $(0,030$ a 0,040$)$ e muito alto $(>0,040)$.

\section{FATOR TOPOGRÁFICO (LS)}

O referido fator foi estimado por meio do MDS-RTCALPSRP076726840 (Path 81, Frame 6840), resolução espacial de 12,5×12,5m. Utilizou-se o módulo de Análise do Terreno (Hidrologia) disponível no software Open Source SAGA (System for Automated Geoscientific Analyses), o qual encontra-se implementado um algoritmo com rotina de cálculo do fator $\mathbf{L}$, desenvolvida por Desmet e Govers (1996), bem como o fator S, desenvolvida por Nearing (1997).Após a estimativa do fator LS, o mesmo foi reamostrado em $30 \times 30 \mathrm{~m}$ de resolução espacial.

\section{FATOR USOE MANEJO (C)}

Para determinar o Fator C, baseou-se na Carta de Uso e Ocupação do Solo para o ano de 2015. Este produto cartográfico foi elaborado por meio das técnicas de sensoriamento remoto. Para isso foi utilizado algumas imagens (B6, B5 e B4) oriundas dos sensores do satélite Landsat 8, Quadro 2.

De posse das imagens (sem correção), visando melhorar o contraste e a obtenção de valores da resposta espectral (reflectância), de forma que aumentasse a eficiência na discriminação dos alvos, bem como na acurácia da classificação, realizou-se os seguintes procedimentos metodológicos, divididos em duas etapas principais: Correção atmosférica (Método DOS-3, disponível no software Open Source GRASSGIS 7.0.4, especificamente no plugini.landsar.toar) e Correção Topográfica (processada por meio do modelo de iluminação (i) e do método de correção - C,plugin i.topo.corr, também disponível no software Open SourceGRASSGIS 7.0.4). Após as correções, seguiu-se para a classificação do tipo "pixel a pixel", supervisionada, processada por meio do algoritmo de

$\begin{array}{llllll}\text { Caminhos de Geografia } & \text { Uberlândia - MG } & \text { v. 19, n. } 67 & \text { Set/2018 } & \text { p. 16-37 } & \text { Página } 21\end{array}$


classificação Distância Mínima, disponível no software Open Source QGIS 2.14.3, pluginSemiAutomatic Classification Plugin (SCP) desenvolvido por Congedo (2016). Por fim, obteve-se a Carta de Uso e Ocupação do Solo da ADBRJ para o ano de 2015.

Quadro 2: Informações parciais dos metadados das imagens oriundas dos sensores do satélite

\begin{tabular}{|c|c|c|c|c|c|c|}
\hline Entidade ID & $\begin{array}{c}\text { LandSat } \\
\text { (Sensor) }\end{array}$ & $\begin{array}{c}\text { Dandsat de } \\
\text { aquisição }\end{array}$ & Path & Row & $\begin{array}{c}\text { Elevação } \\
\left.\text { Solar( }{ }^{\circ}\right)\end{array}$ & $\begin{array}{c}\text { Azimute Solar } \\
\left({ }^{\circ}\right)\end{array}$ \\
\hline LC82180722015163LGN00 & $8($ OLI) & $12 / 06 / 2015$ & 218 & 72 & 40,2261493 & 36,52855067 \\
\hline
\end{tabular}

Fonte: USGS, 2016.

Em seguida, diante da diversidade e discrepância dos valores Fator $\mathbf{C}$ encontrados na literatura, optou-se por trabalhos elaborados em parcelas experimentais de perdas de solo sob condições físicas e climáticas semelhantes à área de estudo. Para cada classe de Uso do Solo, foi atribuído um Fator C, Quadro 3.É importante ressaltar que tais valores do Fator C, representam uma média da variabilidade temporal e espacial da cultura (classe) em análise, podendo variar, para mais ou para menos, conforme as estações do ano. Para as classes Cidade/Distrito e Reservatório (Espelho d'água), atribuiu-se valores iguais a zero.

Quadro 3. Valores do Fator $\mathbf{C}$ adotados para os diferentes tipos de cobertura do solo na ADBRJ.

\begin{tabular}{|l|r|r|}
\hline \multicolumn{1}{|c|}{ Tipo de Cobertura } & Fator - C & \multicolumn{1}{c|}{ Fonte } \\
\hline Solo Exposto & 1,0000 & (WISCHMEIER; SMITH, 1978) \\
\hline Formações Florestais & 0,0340 & (GALDINO et al., 2003) \\
\hline Formações Savânicas & 0,1290 & (GALDINO et al., 2003) \\
\hline Pastagens(Baixo/Médio Degradação) & 0,0143 & (GALDINO, 2012) \\
\hline Silvicultura(Eucalipto) & 0,1200 & (SILVA et al., 2014) \\
\hline
\end{tabular}

\section{fator Práticas Conservacionistas (P)}

A determinação deste fator se deu, primeiramente, a partir das visitas de campo realizadas na área de estudo. Em especial, nas áreas de Pastagens e Silvicultura, observou-se atentamente as práticas conservacionistas, tais como: plantio morro abaixo, plantio em contorno, cordões vegetais, terraceamento, caixa de retenção e detenção. Em seguida, estabeleceu-se os valores de Fator $\mathbf{P}$ para cada tipo de cobertura e práticas conservacionista observadas, de acordo com os autores referenciados no Quadro 4.

Quadro 4: Valores do Fator P adotados para os diferentes tipos de cobertura do solo na ADBRJ.

\begin{tabular}{|c|c|c|}
\hline Tipo de Cobertura & Fator - P & Fonte \\
\hline Solo Exposto & 1,0 & (BERTONI e LOMBARDI NETO, 2014a) \\
\hline Formações Florestais & 1,0 & (BERTONI e LOMBARDI NETO, 2014a) \\
\hline Formações Savânicas & 1,0 & (BERTONI e LOMBARDI NETO, 2014a) \\
\hline Pastagens (Baixo/Médio Degradação) & 1,0 & (BERTONI e LOMBARDI NETO, 2014a) \\
\hline Silvicultura (Eucalipto) & 0,5 & $\begin{array}{r}\text { (BERTONI e LOMBARDI NETO, 2014a; SILVA et } \\
\text { al., 2014) }\end{array}$ \\
\hline
\end{tabular}

$\begin{array}{llllll}\text { Caminhos de Geografia } & \text { Uberlândia - MG } & \text { v. 19, n. } 67 & \text { Set/2018 } & \text { p. 16-37 } & \text { Página } 22\end{array}$ 


\section{Estimativa Da Perda De Solo por Erosão laminar}

A quantificação média anual da Perda de Solo por Erosão Laminar na ADBRJ, foi estimada por meio da fórmula (8).

Em que A é Perda de Solo por Erosão Laminar (PSEL), conhecida como Universal Soil Loss Equation (USLE) ou Equação Universal de Perda de Solo (EUPS), cuja unidade é t.ha ${ }^{-1}$. ano-1 ${ }^{-1}$ O fator $\mathbf{R}$ é o Fator Erosividade(MJ.mm. $\mathrm{h}^{-1} \cdot \mathrm{ha}^{-1}$.ano ${ }^{-1}$ ), $\mathbf{K}$ é o Fator Erodibilidade (t.ha.h.ha ${ }^{-1} \cdot \mathrm{MJ}^{-1} \cdot \mathrm{mm}^{-1}$ ) e LS é o Fator Topográfico (Adimensional). Já os fatores $\mathbf{C}$ e $\mathbf{P}$ são, respectivamente, Fator de Uso-Manejo e Práticas Conservacionistas, ambos adimensionais.

Após os fatores $\mathbf{R}, \mathbf{K}$, LS, C e $\mathbf{P}$ serem alinhados com a mesma resolução espacial $(30 \times 30 \mathrm{~m})$ na plataforma SIG do software QGIS, a sistematização da Carta de Erosão Laminar na ADBRJ procedeu-se com base na chave de interpretação proposta por CARVALHO (1994, apud BORGES, 2009, p.67), estratificada nos seguintes níveis: Nula a pequena $\left(0-10 \mathrm{t}^{-\mathrm{ha}^{-1}}\right.$. ano- $\left.{ }^{-1}\right)$, Moderada (10 15 t. ha ${ }^{-1}$. ano $\left.{ }^{-1}\right)$, Média $\left(15-50\right.$ t. ha ${ }^{-1}$. ano $\left.{ }^{-1}\right)$, Média a Forte $\left(50-120\right.$ t. ha $^{-1}$. ano $\left.{ }^{-1}\right)$, Forte $(120-200$ t. ha ${ }^{-1}$. ano $\left.{ }^{-1}\right)$, Muito Forte $\left(>200\right.$ t. ha $a^{-1}$. ano $\left.{ }^{-1}\right)$.

Por último, determinou-se o Risco de Erosão Laminar (REL), fórmula (9).

REL $=\frac{\text { PSEL }}{T}$

Em que PSEL é Perda de Solo por Erosão Laminar e (T) é a Tolerância de Perda de Solo, ambos em t.ha' ${ }^{-1}$. ano ${ }^{-1}$.

Para efeito de cálculo e estimativa da magnitude do Risco de Erosão Laminar, priorizou-se em obter valor de (T) oriundos de solos com características semelhantes, até ao $4^{\circ}$ Nível do Sistema Brasileiro de Classificação de Solos proposto pela Embrapa (2013), encontrados na ADBRJ, Quadro 5.

A sistematização da Carta de Risco de Erosão da ADBRJ foi elaborada com base na chave de interpretação proposta por Lagrotti (2000), classificada nos seguintes níveis: Muito baixo (valores menores que 1); Baixo (entre 1-2); Moderado (2-5); Alto (5-10) e Muito alto (>10).

Ressalta-se que os pontos amostrais georreferenciados e a validação dos resultados foram determinados por meio de um Microrreceptor SmartphoneGNSS (Motorola Moto G 3) em interface dos aplicativos livres PDF Maps e Mobile Topographer, os quais substituíram a função de um Receptor GNSS de Navegação convencional.

Quadro 5: Tolerância de Perda de Solo (T).

\begin{tabular}{|c|c|c|}
\hline Unidades Pedológicas & $\mathbf{T}-\left(\right.$ t.ha $_{1}^{-1}$ ano $^{-}$ & Fonte \\
\hline CAMBISSOLO HÁPLICO Tb Distrófico típico - 1 & $4,34^{*}$ & $\begin{array}{l}\text { (MANNIGEL et al., 2002; CORRÊA; } \\
\text { MORAES; PINTO, 2015). }\end{array}$ \\
\hline CAMBISSOLO HÁPLICO Tb Distrófico típico - 2 & $4,34^{*}$ & $\begin{array}{l}\text { ((MANNIGEL et al., 2002; CORRÊA; } \\
\text { MORAES; PINTO, 2015). }\end{array}$ \\
\hline LATOSSOLO VERMELHO-AMARELO Distrófico típico & 11,53 & (MANNIGEL et al., 2002) \\
\hline NEOSSOLO LITÓLICO Distrófico típico & 5,28 & (DEMARCHI e ZIMBACK, 2014) \\
\hline NITOSSOLO VERMELHO Eutrófico típico & $13,83^{*}$ & $\begin{array}{c}\text { (MANNIGEL et al., 2002)(DEMARCHI e } \\
\text { ZIMBACK, 2014) }\end{array}$ \\
\hline
\end{tabular}

*Valor médio. 


\section{RESULTADOS E DISCUSSÃO}

\section{FATOR EROSIVIDADE (R)}

A erosividade total anual, obtida na ADBRJ, foi de 7.511,2 MJ.mm.h ${ }^{-1} \cdot \mathrm{ha}^{-1}$.ano ${ }^{-1}$, Tabela 1 , ou seja, índice de erosividade forte, conforme a classificação proposta por Foster et al. (1981). O período chuvoso apresentou valor acumulado semestral de 6.999,6 MJ.mm. ${ }^{-1} \cdot \mathrm{ha}^{-1}$, Erosividade MédioForte,o que representa $93,19 \%$ do total anual acumulado. Já o período seco apresenta-se 511,6 MJ.mm. $h^{-1} \cdot$ ha $^{-1} \cdot$ semestre $^{-1}$, Erosividade Baixa, o que corresponde $6,81 \%$ do total anual.

Tabela 1: Erosividade média mensal na ADBRJ ao longo do ano.

\begin{tabular}{cc}
\hline Mês & $\mathbf{R}\left(\mathbf{M J} \cdot \mathbf{m m} \cdot \mathbf{h}^{-1} \cdot \mathbf{h a}^{-1} \cdot \mathbf{a n o}^{-1}\right)$ \\
\hline JAN & 1278,2 \\
FEV & 553,9 \\
MAR & 698,7 \\
ABR & 141,6 \\
MAI & 75,3 \\
JUN & 70,5 \\
JUL & 70,2 \\
AGO & 70,1 \\
SET & 83,9 \\
OUT & 344,4 \\
NOV & 1664,1 \\
DEZ & 2460,4 \\
\hline Total &
\end{tabular}

\section{FATOR ERODIBILIDADE (K)}

A ADBRJ apresentou, em geral, erodibilidade muito alta, ou seja, 0,0429 t.h.MJ ${ }^{-1} \cdot \mathrm{mm}^{-1}$, variando de 0,0354 até 0,0554 t.h. $\mathrm{MJ}^{-1} \cdot \mathrm{mm}^{-1}$. Destacou-se o Latossolo Vermelho-Amarelo Distrófico típico, com textura argilosa (14,00\% de areia, $77,30 \%$ de argila, $8,70 \%$ de silte e 3,96\% de M.O), por apresentar a menor erodibilidade, ou seja, de 0,0354 t.h. $\mathrm{MJ}^{-1} \cdot \mathrm{mm}^{-1}$. Já o Neossolo Litólico Distrófico típico, com variação de textura média arenosa-argilosa à siltosa $(32,00 \%$ de areia, $27,34 \%$ de argila, $40,66 \%$ de silte e $2,46 \%$ de M.O), apresentou a maior erodibilidade, ou seja, 0,0554 t.h.MJ' ${ }^{-1} . \mathrm{mm}^{-1}$.

O Cambissolo Háplico Tb Distrófico típico - 1, textura argilo-siltosa $(62,75 \%$ de areia, $22,00 \%$ de argila, $15,25 \%$ de silte e $1,82 \%$ de M.O) e o Cambissolo Háplico Tb Distrófico típico - 2, textura argilosa $(9,25 \%$ de areia, $53,75 \%$ de argila, $37,00 \%$ de silte e $3,55 \%$ de M.O), mesmo com características texturais distintas, quando modeladas na equação proposta de erodibilidade, culminaram em valores relativamente próximos, 0,0432 e 0,0445 t.h.MJ $\mathrm{J}^{-1} \cdot \mathrm{mm}^{-1}$, respectivamente (Tabela 2).

Tabela 2: Erodibilidade média $(\overline{\mathbf{K}})$ das unidades pedológicas na ADBRJ.

\begin{tabular}{l|c|c|c}
\hline \multicolumn{1}{c}{ Unidades Pedológicas } & \multicolumn{3}{|c}{ Fator $\mathbf{k}-\left(\mathrm{t} \cdot \mathrm{h} \cdot \mathrm{MJ}^{-1} \cdot \mathrm{mm}^{-1}\right)$} \\
\cline { 2 - 4 } & $\mathbf{K}_{\mathbf{M I N}}$ & $\overline{\mathbf{K}}$ & $\mathbf{K}_{\mathbf{M A X}}$ \\
\hline Cambissolo Háplico Tb Distrófico típico - 1 & 0,0320 & 0,0432 & 0,0526 \\
Cambissolo Háplico Tb Distrófico típico - 2 & 0,0423 & 0,0445 & 0,0476 \\
Latossolo Vermelho-Amarelo Distrófico típico & 0,0352 & 0,0354 & 0,0356 \\
Neossolo Litólico Distrófico típico & 0,0521 & 0,0554 & 0,0590 \\
Nitossolo Vermelho Eutrófico típico & 0,0336 & 0,0412 & 0,0456 \\
\hline
\end{tabular}


Já o Nitossolo Vermelho Eutrófico típico, com textura argilosa $(5,75 \%$ de areia, $59,75 \%$ de argila, $34,50 \%$ de silte e $4,45 \%$ de M.O) encontra-se como o segundo solo menos vulnerável na ADBRJ, erodibilidade média de 0,0412 t.h.MJ ${ }^{-1} \cdot \mathrm{mm}^{-1}$.

\section{FATOR TOPOGRÁFICO (LS)}

A ADBRJ possui um Fator Topográfico (LS) com variabilidade espacial expressiva, com valores variando de 0,03 a 175,84, o que confirma a rugosidade e heterogeneidade do relevo (Figura 3 ). Os menores valores $(0,03)$ são encontrados nos topos de morros, Chapada da Onça, bem como nas altitudes inferiores a $720 \mathrm{~m}$ da bacia. Em tais áreas predominam, com $60,9 \%$ da área total, valores entre 0,03 a 1,6. Já os maiores valores LS, são encontrados nas vertentes com rampas retilíneas, côncavas e convexas. Valores de LS superiores a 8,0 representam $6,07 \%$ da ADBRJ. O valor médio observado do Fator Topográfico (LS) foi de 2,75.

Figura 3: Distribuição espacial do Fator Topográfico (LS) da ADBRJ.

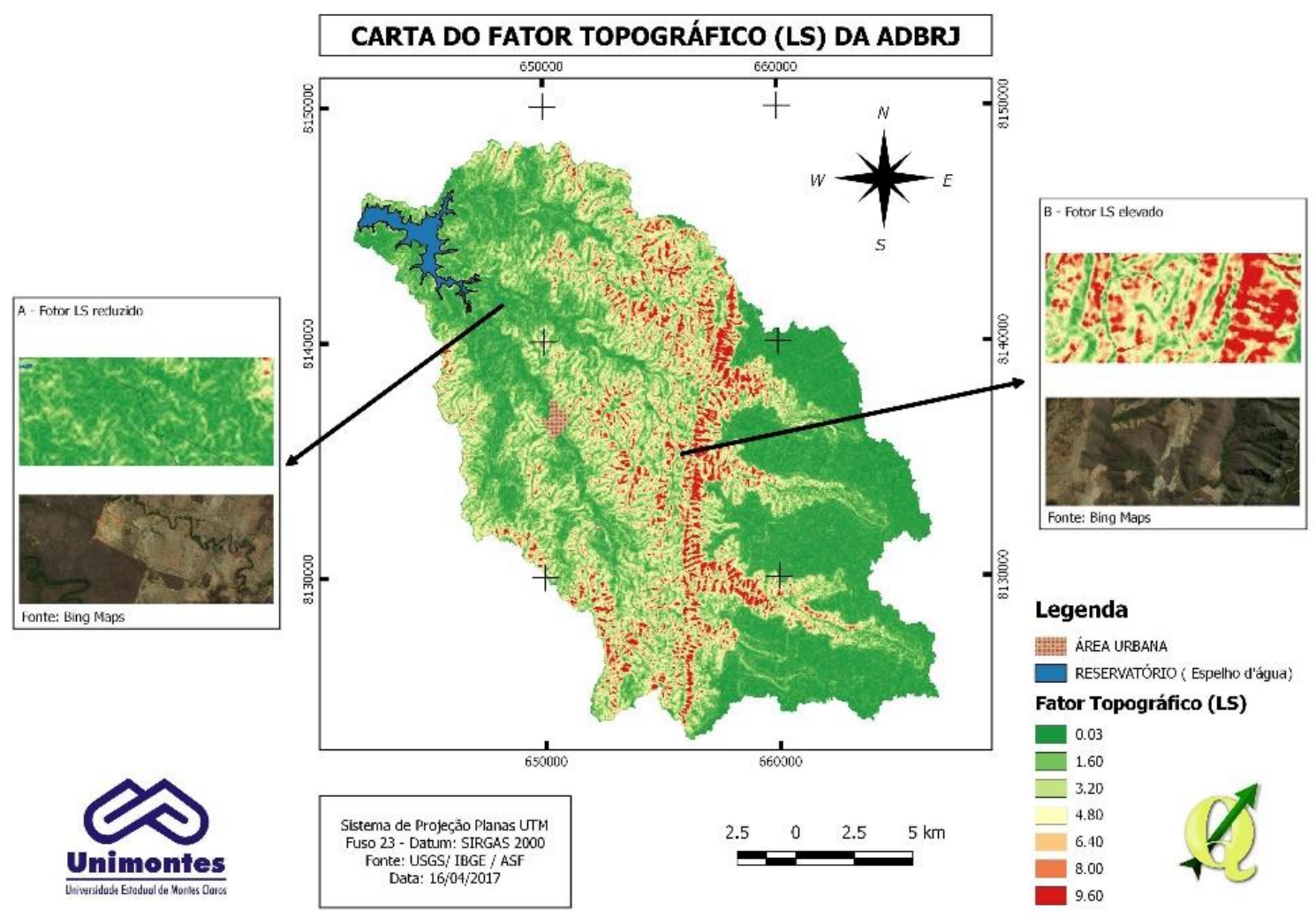

O valor máximo $(175,84)$ é observado nas áreas montanhosas, onde estão localizadas as Escarpas Erosivas ou Abruptos do Espinhaço. Em média, tais áreas possuem rampas com comprimento de $800 \mathrm{~m}$, em alguns casos podem atingir valores acima de $1.300 \mathrm{~m}$ de extensão, conforme observado na Figura 4 (a) e Figura 4 (b), respectivamente.

Os Abruptos do Espinhaço da ADBRJ, por estarem localizados nas regiões de maiores altitudes e também por possuírem rampas mais longas e mais íngremes, estão condicionados, naturalmente, às maiores velocidades do escoamento superficial. Tais condições favorecem a formação da erosão laminar, sulcos e até mesmo voçorocas, pois o fluxo do escoamento superficial tende a ser mais concentrado nos canais de drenagem (perenes, intermitentes ou até mesmo efêmeros), bem como na superfície do modelado, transportando assim, maiores quantidades de partículas do solo. 
Fiqura 4: Paisaqens das Escarpas Erosivas ou Abruptos do Espinhaço na ADBRJ.
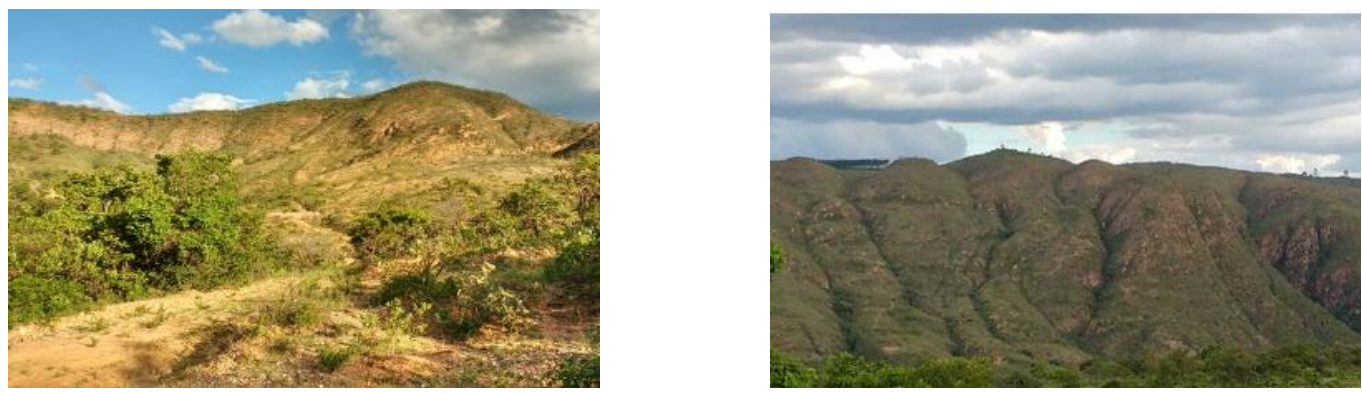

(a)

(b)

Autor: OLIVEIRA, W. F. (2016).

\section{FATOR USO e MANEJO (C)}

As Áreas Antropizadas predominavam, no ano de 2015 , com $56,87 \%$ da área total da ADBRJ, dividindo-se em Pastagens (30,70\%), Silvicultura (24,53\%), Reservatório (Espelho d'água) $(1,33 \%)$ e Cidade/Distrito $(0,31 \%)$. As áreas de Pastagem, ao contrário da Silvicultura, destacam-se pela heterogeneidade quanto aos níveis de degradação (Figura 5).

Figura 5: Níveis de degradação das pastagens encontradas na ADBRJ. Pastagem não degradada (a), Baixo/médio nível de degradação (b) e Alto nível de degradação (c), conforme Galdino (2012).

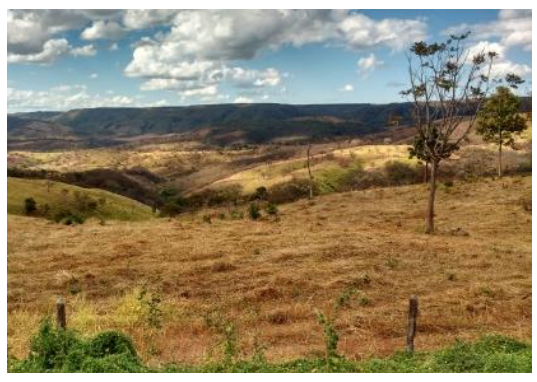

(a)

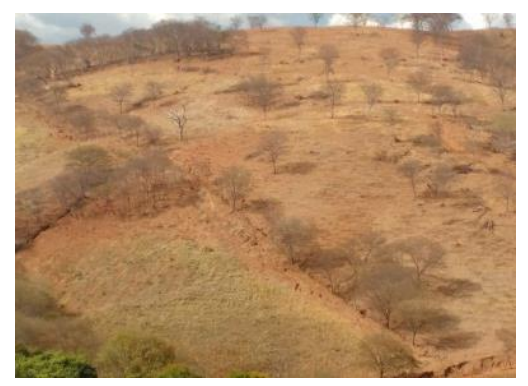

(b)

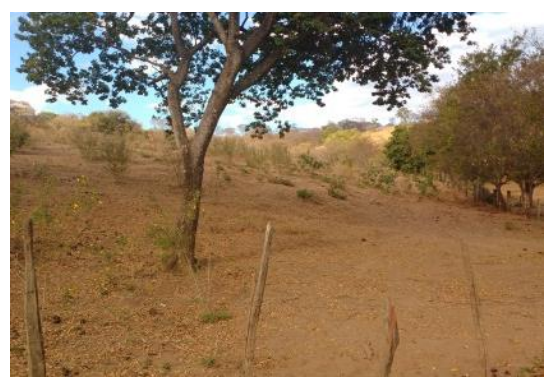

(c)

Autor: OLIVEIRA. W. F. (2016)..

O valor do Fator $C$ considerado para as Pastagens foi de 0,0143 , o qual corresponde baixo/médio nível de degradação. Isso equivale uma pastagem de 20 a 45\% com área de solo exposto (GALDINO, 2012). Esse cenário representa, em média, as condições das pastagens da área de estudo, onde à medida que ocorre a diminuição da cobertura da superfície pelo dossel e resíduos (Solo exposto > $45 \%$ ), aumenta o nível de degradação das pastagens e, consequentemente, aumento do valor de C, ou seja, eleva-se o nível de degradação. Caso o contrário, com a redução da área de solo exposto ( $\leq$ $20 \%$ ), o valor de $C$ também é reduzido, diminuindo assim o potencial de degradação no que se refere à perda de solo. Grande parte das Áreas Descobertas (Solo Exposto) encontra-se entremeadas às áreas de Pastagens, com 1,33\% da área total da bacia, evidenciando a ocorrência da erosão hídrica 
laminar, o que justifica $\mathrm{C}=1,0$ em tais áreas. Conforme apontado por Pruski (2006), as pastagens fornecem boa proteção ao solo contra a erosão. Porém, quando mal manejadas, podem prejudicar o cumprimento dessa função, uma vez que o pisoteio intensivo pode torná-la escassa.

Já as Áreas Naturais, juntas somavam 41,79\%, sendo 37,52\% constituída de Formações Florestais e $4,27 \%$ de Formações Savânicas. Áreas Naturais, em especial as Formações Florestais, desempenham um papel importante no controle das perdas de solo, devido à uniformidade da cobertura vegetal ao longo do ano. As espécies arbóreas mais densas, por meio da estrutura do dossel, das folhas e do resíduo vegetal, minimizam os impactos diretos das gotas de chuva ao atingirem o solo, pois atuam reduzindo consideravelmente, a velocidade e a força de impacto de cada gota no solo (MARTINS et al., 2010; BERTONI e LOMBARDI NETO, 2014b). Tais fatores são relevantes e justifica o baixo valor encontrado para o Fator $C(0,034)$, que culmina em termos práticos, na maior infiltração de água no solo, menor escoamento superficial e consequentemente, menor perda de solo.

\section{fator Práticas Conservacionistas (P)}

Durante as visitas realizadas na área de estudo, observou-se a ocorrência de práticas conservacionistas apenas na área de Silvicultura (Eucalipto), presente em 24,53 \% da área total da bacia, ano de 2015. As práticas correntes em tais áreas são de caráter edáficas, tais como: controle de queimadas (aceiro roçado de mais ou menos cinco metros de largura), adubação químicoorgânica, calagem e manutenção da cobertura vegetal nos talhões de plantio. Também são comuns as práticas conservacionistas de caráter mecânico (estradas com boa manutenção, terraceamento e caixa de contenção) e vegetativo (cultivo em contorno e cobertura morta) (Figura 6 (a)). Para a referida área, estabeleceu-se 0,5 como o Fator $P$.

É importante ressaltar que, algumas práticas de conservação do solo, de caráter mecânico (barraginhas e caixa de contenção), também são utilizadas em alguns trechos das principais estradas vicinais da ADBRJ.

Figura 6: Presença de práticas conservacionistas (edáfica, vegetativa e mecânica) em área de Silvicultura (a) e ausência de práticas conservacionistas em área de Pastagem (b), ambas
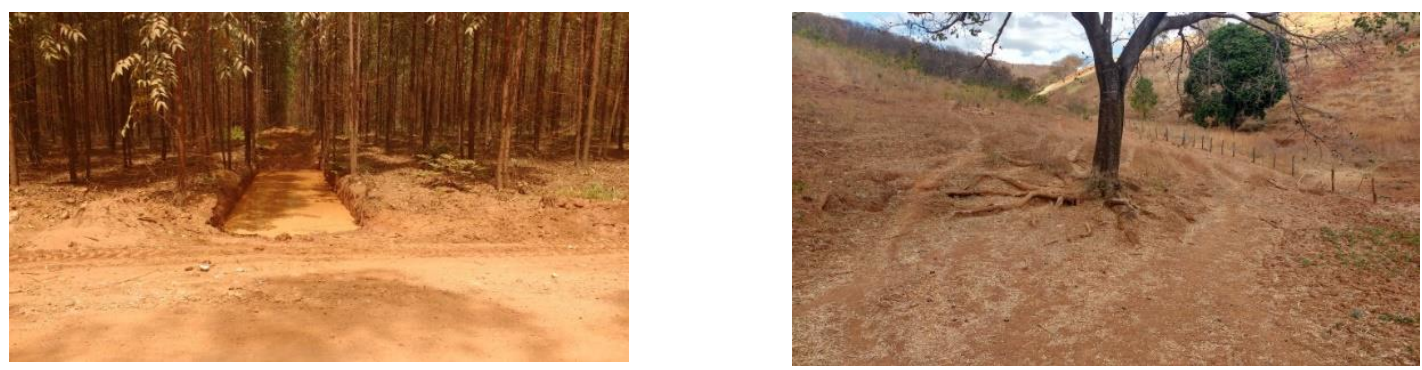

(a)

(b)

Autor: OLIVEIRA, W. F. (2016)

Apesar de ter sido detectada a ocorrência de pastagens com baixo nível de degradação, a adoção de práticas conservacionista, em termos gerais, é praticamente inexistente, como exemplo mostrado na Figura 6 (b). Em vista disso, o valor atribuído para o Fator $\mathrm{P}$ em tais áreas foi 1,0. Para as demais áreas (Áreas Naturais), também foi atribuído 1,0 para o Fator $\mathrm{P}$, pois não há nenhuma estrutura artificial ou interferência humana, cuja finalidade seja implantação de práticas conservacionistas. 


\section{A - Perda De Solo por ERosão laminar (PSEL)}

A ADBRJ apresentou perda média de solo por erosão laminar de 48,01 t.ha $^{-1}$.ano ${ }^{-1}$, considerado como magnitude Média. As áreas com pequeno nível de perda de solo, ou seja, perdas inferiores a 10 tha $^{-1}$.ano 1 , representam $36,31 \%$ da área total da bacia. Tais áreas encontram-se distribuídas nas menores altitudes $(<700 \mathrm{~m})$, onde há ocorrência do Nitossolo Vermelho, assim como nas altitudes superiores a $1.050 \mathrm{~m}$, com ocorrência predominante do Latossolo Vermelho-Amarelo (Figura 7). Em relação às unidades pedológicas de Latossolo e o Nitossolo da ADBRJ, ambas possuem textura argilosa e também apresentam os maiores valores de matéria orgânica, com 3,96\% e 4,4\%, respectivamente. É importante ressaltar que a matéria orgânica é um dos condicionantes de agregação de partículas, melhoria na estrutura do solo e, consequentemente, redutora da erodibilidade.

As perdas expressivas, nível de erosão Forte a Muito forte, juntas contabilizam 6,67\% da ADBRJ, Tabela 4. Essas áreas ocorrem, expressivamente, no centro-latitudinal da bacia, onde predomina a unidade pedológica Neossolo Litólico. Em tais áreas, as práticas conservacionistas são praticamente inexistentes, o solo (32,01\% de areia, $27,33 \%$ de argila, $40,66 \%$ de silte e2,46\% de matéria orgânica) é raso, o relevo é mais acidentado, a vegetação é mais esparsa (Formações Savânicas) e com presença de solo exposto. Em situações extremas, estima-se que as perdas podem superar 120 t.ha $^{-1} \cdot$ ano $^{-1}$.

Tabela 4: Quantitativo das classes da PSEL na ADBRJ, 2015.

\begin{tabular}{cccc}
\hline Nível de Erosão & PSEL $\left(\right.$ t.ha $^{-1} \cdot$ ano $^{-1}$ ) & Hectare (ha) & (\%) \\
\hline Nulo - Pequeno & $<10$ & $12.748,1$ & 36,31 \\
Moderado & $10-15$ & $5.108,368$ & 14,55 \\
Médio & $15-50$ & $10.202,69$ & 29,06 \\
Médio - Forte & $50-120$ & $4.708,125$ & 13,41 \\
Forte & $120-200$ & 933,901 & 2,66 \\
Muito Forte & $>200$ & $1.407,873$ & 4,01 \\
\hline & Total & $\mathbf{3 5 . 1 0 9 , 0 6}$ & $\mathbf{1 0 0}$ \\
\hline
\end{tabular}

O entorno das nascentes dos principais Rios e Córregos (Saracura, Tiadósia, Do Brejinho e Dos Casados) da ADBRJ é compreendido por relevo Suave Ondulado a Ondulado, com declividade variando de 3 a $20 \%$. A vegetação é do tipo Formações Florestais (Mata Ciliar) e Savânicas (Cerrado Típico e Rupestre), razoavelmente preservada, e o solo predominante é do tipo Cambissolo Háplico Tb Distrófico -1. Em algumas áreas, as nascentes encontram-se cercadas nos limites da Área de Preservação Permanente (APP), com algumas práticas conservacionistas (Caixa de retenção de água pluvial) à montante. Tais características colaboram na redução da PSEL no entorno das mesmas, com valores abaixo de 10 t.ha ${ }^{1}$.ano ${ }^{-1}$ (Figura 7).

\section{RISCO DE EROSÃo LAMINAR-REL}

A ADBRJ apresentou variabilidade espacial de REL bem expressiva, com valores menores que 1,0 (Muito baixo) a valores maiores que 10,0 (Muito alto), onde as perdas superam dez vezes ou mais a formação de solo. Os maiores valores são encontrados no centro-latitudinal da bacia, onde ocorrem os Abruptos do Espinhaço (Escarpas Erosivas), bem como a presença do solo mais erodível da bacia, o Neossolo. A variabilidade espacial do REL nas áreas ocupadas por Silvicultura (Eucalipto) pode ser encontrada na Figura 8(a). 
Figura 7: Perda de Solo por Erosão Laminar (PSEL) na ADBRJ, 2015.

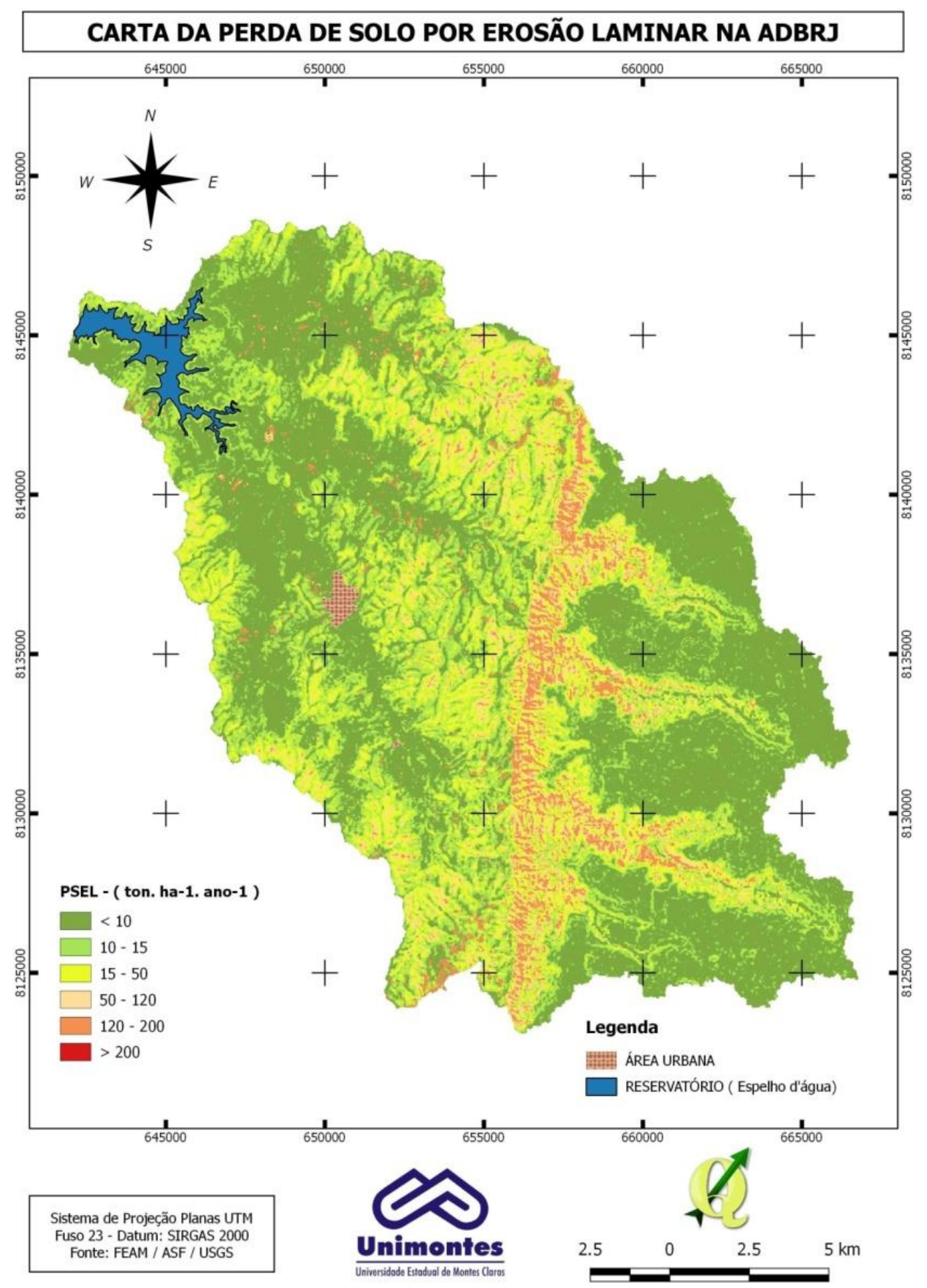


Figura 8: Risco de Erosão Laminar nas áreas de Silvicultura localizadas na ADBRJ, 2015

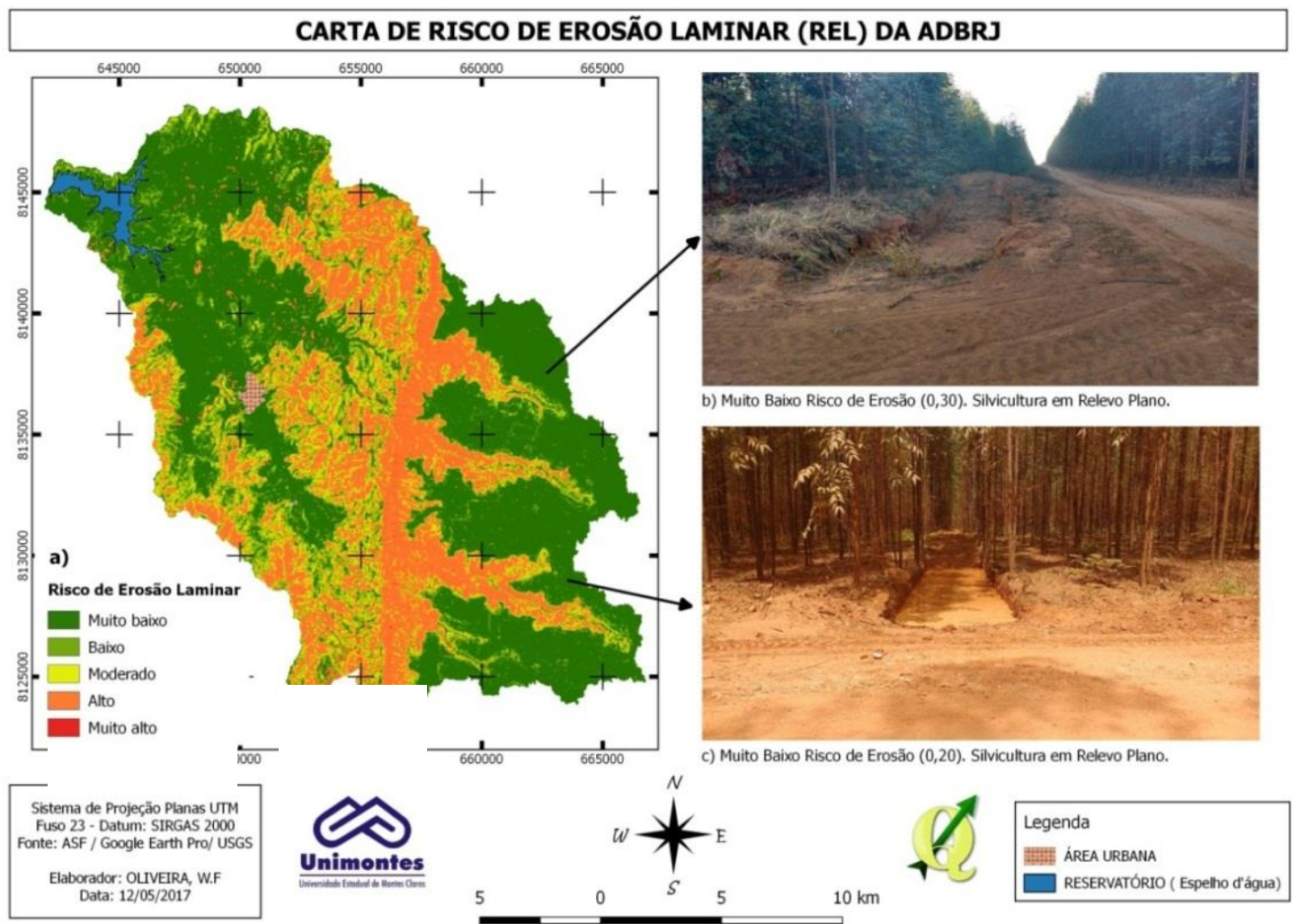

Ressalta-se que a referida Carta de Risco de Erosão Laminar no formato ".TIFF" foi exportada em "PDF", uma vez georreferenciado, para o aplicativo PDF Maps, instalado no Smartphone GNSS (Motorola Moto G3), de onde foi possível realizar a navegação em campo e, consequentemente, a validação dos pontos amostrais predeterminados aleatoriamente.

As áreas de Silvicultura (Eucalipto) encontram-se em relevo plano (Baixo fator LS), onde o solo é do tipo Latossolo Vermelho-Amarelo e há práticas conservacionistas do solo (plantio em contorno, caixa de retenção de água pluvial e estradas relativamente conservadas), bem como técnicas de prevenção e combate a incêndio (construções de aceiros, política de conscientização nas comunidades vizinhas e brigada florestal), como mostra as Figuras 8 (b) e (c). Em tais áreas o REL varia de Muito baixo a Baixo, em alguns casos, as perdas não superam a formação de solo, ou seja, a tolerância média é de 11,53 t.ha $^{-1} \cdot$ ano $^{-1}$ e as perdas são de 10,04 t.ha ${ }^{-1} \cdot$ ano $^{-1}$.

Os baixos valores das perdas de solo e risco de erosão, encontrados nas áreas de Silvicultura, vai ao encontro do estudo realizado por Pires et al. (2006), o qual os pesquisadores identificaram que, para todos os sistemas de manejo do Eucalipto investigados, os mesmos apresentaram perdas de solo inferiores ao valor limite de tolerância. Os referidos autores destacaram que o Eucalipto quando bem manejado, entre os sistemas florestais, é o que mais se aproxima da mata nativa em termos de perdas de solo, indicando assim, maior sustentabilidade desse sistema no que diz respeito à erosão hídrica.

As classes de Muito baixo e Baixo de Risco de erosão laminar somaram, aproximadamente, $52 \%$ da área total da bacia, Tabela 5 . E concentram na parte alta e baixa da bacia, sendo que essas áreas possui relevo menos acidentado.

Já na região centro-noroeste da bacia, as perdas são ligeiramente mais expressivas quanto à tolerância, a exemplo das áreas com ocorrência de Nitossolo Vermelho, onde a tolerância é de 13,83 t.ha ${ }^{-1}$.ano- ${ }^{-1}$ e as perdas são de 23,50 t.ha ${ }^{-1}$.ano ${ }^{-1}$, ou seja, há baixo risco de erosão, (Figura 9). Nessas áreas há o cultivo das Pastagens mais conservadas da bacia, bem como a presença de Mata Ciliar e Mata Seca, as quais colaboram na redução das perdas de solo.

$\begin{array}{llllll}\text { Caminhos de Geografia } & \text { Uberlândia - MG } & \text { v. 19, n. } 67 & \text { Set/2018 } & \text { p. 16-37 } & \text { Página } 30\end{array}$


Tabela 5: Classes de Risco de Erosão Laminar (REL) na ADBRJ, 2015.

\begin{tabular}{ccc}
\hline REL & Hectare $(\mathrm{ha})$ & $(\%)$ \\
\hline Muito Baixo & $13.636,36$ & 38,84 \\
Baixo & $4.536,09$ & 12,92 \\
Moderado & $5.382,22$ & 15,33 \\
Alto & $4.255,22$ & 12,12 \\
Muito Alto & $7.299,17$ & 20,79 \\
\hline Total & $\mathbf{3 5 . 1 0 9 , 0 6}$ & $\mathbf{1 0 0}$
\end{tabular}

Figura 9: Risco de Erosão Laminar em áreas de Pastagens na ADBRJ.

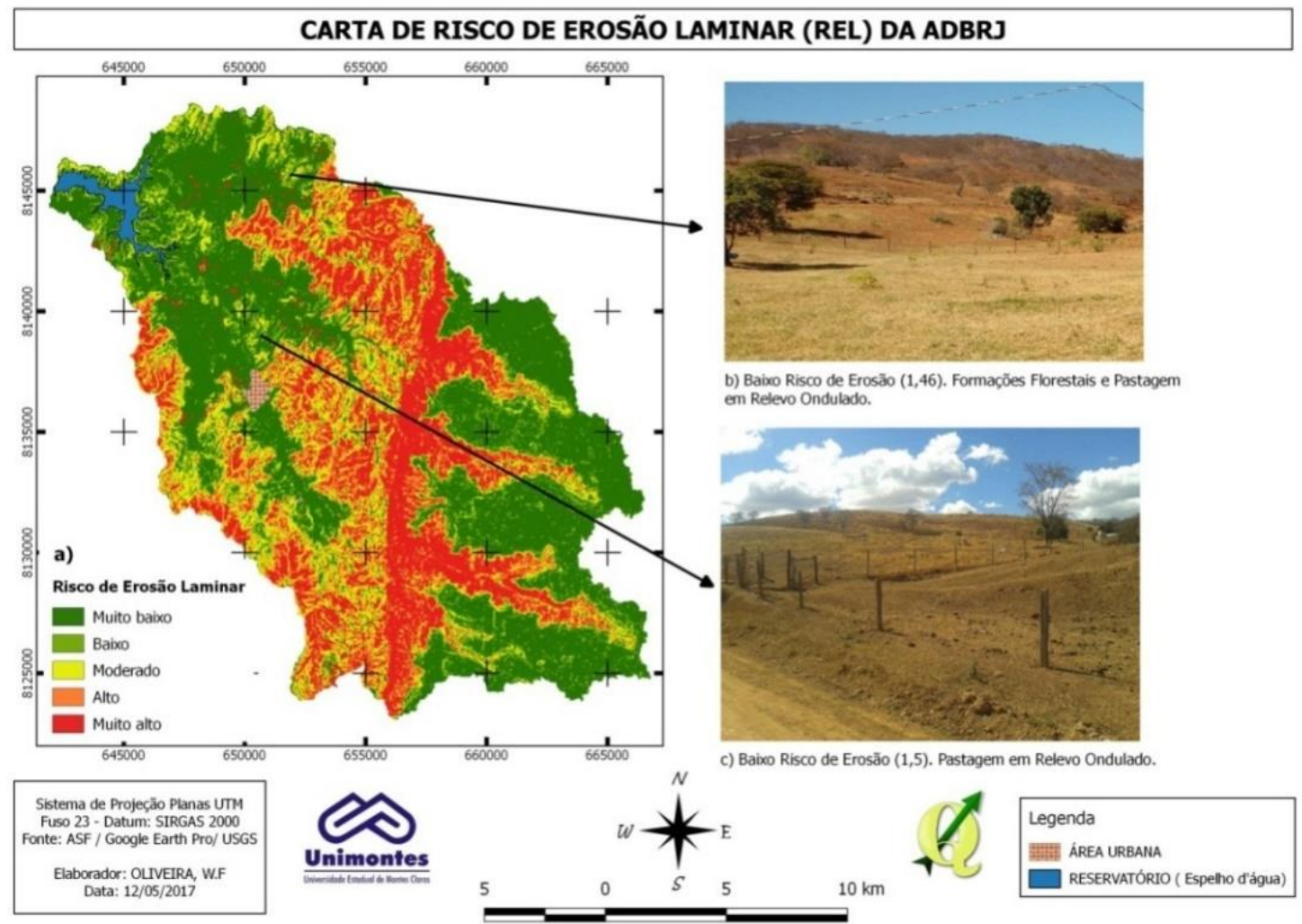

Conforme a Figura 9(b) e (C), o risco de erosão encontra-se baixo, quando na presença de algumas práticas conservacionistas (caixa de retenção e detenção de água pluvial) nas áreas de pastagem. Porém, na ausência das referidas práticas conservacionistas e com a presença de relevo ligeiramente acidentado, o risco eleva-se ao nível moderado. Ressalta-se que alguns trechos das estradas vicinais se encontram em bons estados de conservação. No entorno do Reservatório, onde há Formações Florestais e as declividades são inferiores a $8 \%$, as perdas não superam a tolerância. Sendo assim, o risco de erosão é reduzido para muito baixo, ou seja, menor que um.

As áreas com ocorrência de unidades pedológicas Latossolo e Nitossolo são as que apresentam menores Riscos à Erosão Laminar. Em geral, tais solos são mais profundos, permeáveis e suportam perdas maiores de solo em t.ha ${ }^{-1}$. ano ${ }^{-1}$ (BERTONI e LOMBARDI NETO, 2014a).

Nas áreas de Cambissolo Háplico Tb Distrófico típico - 2, ocupadas por Pastagens, Formações Savânicas (Cerrado típico e Rupestre) e Remanescente de Formações Florestais (Mata Ciliar, de Galeria, Cerradão e Mata Seca), o risco de erosão laminar se eleva significativamente. As perdas médias são de 47,20 t.ha ${ }^{-1}$.ano-1, enquanto a tolerância é de 4,34 t.ha ${ }^{-1}$.ano ${ }^{-1}$, ou seja, em tais áreas predominam o risco de erosão Muito alto. São vários fatores que colaboram para essa situação, tais

\begin{tabular}{llllll}
\hline Caminhos de Geografia & Uberlândia - MG & v. 19, n. 67 & Set/2018 & p. 16-37 & Página 31
\end{tabular}


como: o relevo predominante é forte ondulado (declividade de 20 a 45\%), com algumas áreas montanhosas (declividade de 45 a 75\%), pastagem mal conservada (sem práticas conservacionistas). As referidas áreas ocorrem na região Norte, Centro e Sul da bacia, como exposto na Figura 10(a). Já o remanescente das Formações Florestais (Floresta Estacional Semidecidual) e as Pastagens (resultado do desflorestamento), encontram-se degradadas (presença de sulcos, ravinas e até mesmo voçorocas), conforme Figuras 10 (b) e (c), respectivamente. Nas ocorrências das Formações Savânicas e Florestais, o risco de erosão é reduzido de muito alto para alto e moderado, respectivamente.

Figura 10: Risco de Erosão Laminar em áreas de Pastagens e Remanescentes Florestais na ADBRJ, 2015

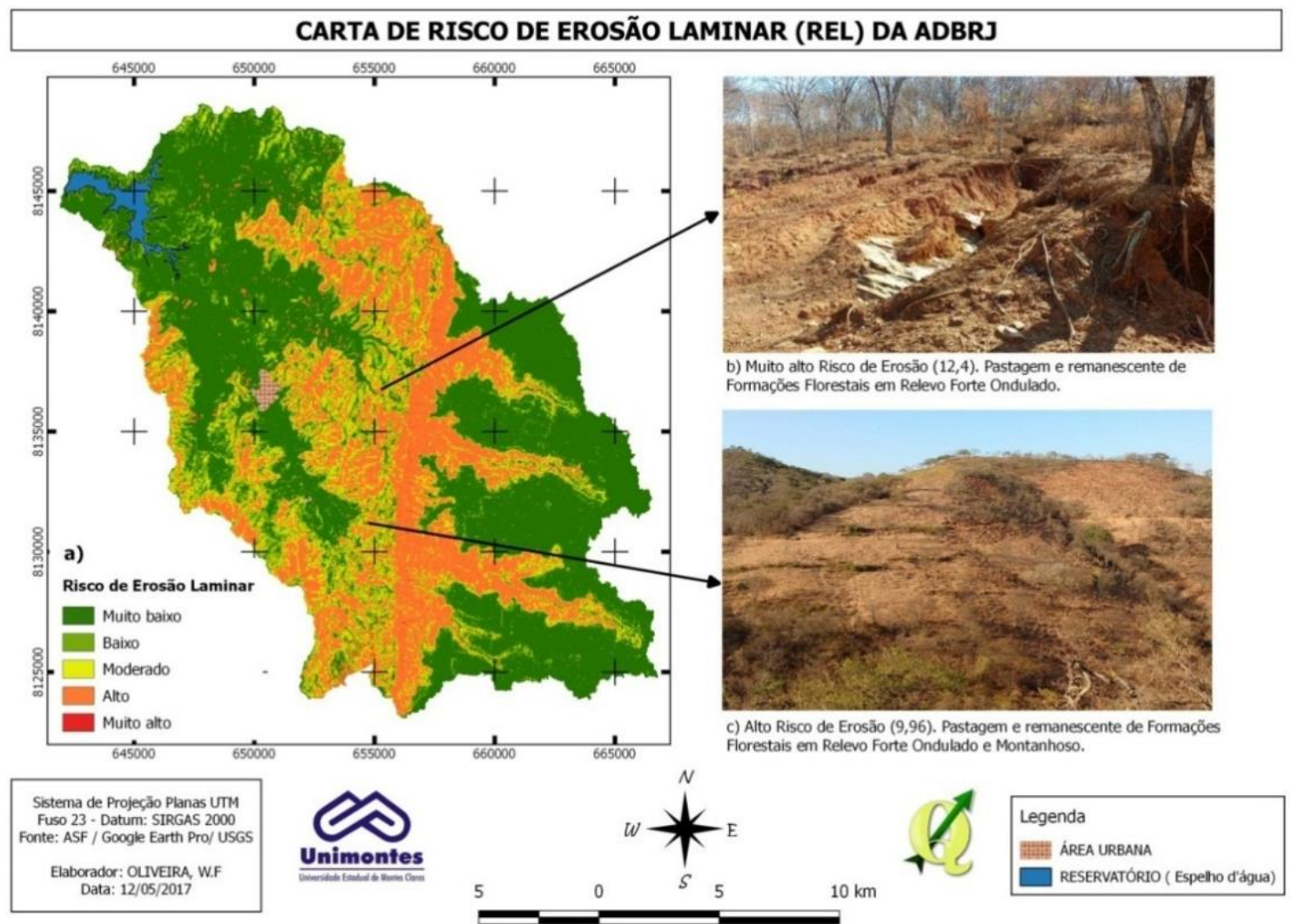

Ressalta-se que o manejo inadequado da pastagem diminui a densidade da cobertura vegetal, surgindo áreas de solos expostos, bem como intensificação do processo de erosão laminar e, consequentemente, torna-se a área, progressivamente, menos fértil e mais vulnerável à erosão (BERTONI e LOMBARDI NETO, 2014c), ou seja, eleva-se a magnitude do risco de erosão laminar.

Já nas áreas de Cambissolo Háplico Tb Distrófico típico-1, ocupadas por Formações Savânicas (Cerrado Típico e Rupestre) e Florestais (Mata Ciliar), a magnitude do risco de erosão é ligeiramente reduzida, com perdas médias de $45,57 \mathrm{t}_{\mathrm{ha}} \mathrm{ha}^{-1}$.ano ${ }^{-1}$. O relevo predominante nessas áreas é ondulado (8 a $20 \%$ de declividade) e, em algumas áreas, há ocorrência de rochas expostas na superfície do terreno.

Perfazem 32,91\% da ADBRJ as áreas de alto e muito alto Risco de Erosão Laminar, com perdas que podem superar os 172,72 t.ha ${ }^{-1}$.ano ${ }^{-1}$. Tais áreas estão localizadas sobre os Neossolos Litólicos, os quais possuem tolerância média de 5,28 t.ha $^{-1}$.ano ${ }^{-1}$. Os Neossolos Litólicos possuem baixo desenvolvimento pedogenético (solos jovens), ou seja, são solos rasos e com baixo teor de material orgânico e argila. Na ADBRJ tais solos estão associados às montanhas, às escarpas erosivas (região de relevo mais dissecado), às Formações Savânicas (Cerrado Rupestre), Florestais (Mata Ciliar e de Galeria) e até mesmo às Formações Campestres (Campo Rupestre). 
Quando há ocorrência das Formações Savânicas, o solo se mostra pedregoso e com resquícios de queimadas clandestinas, cuja prática é no intuito de renovar a cobertura vegetal natural para aproveitamento como pastagem. As queimadas nessas áreas são recorrentes, e ocorrem anualmente no período que antecede as primeiras semanas da estação chuvosa. A erosão é bem evidente nessas áreas, age modificando o relevo por meio da ação das águas pluviais que se escoam (runoff) ao longo das vertentes, formando sulcos, ravinas e até mesmo voçoroca (Figuras11 (b) e (c)).

Figura 11: Risco de Erosão Laminar em Formações Savânicas da ADBRJ, 2015.

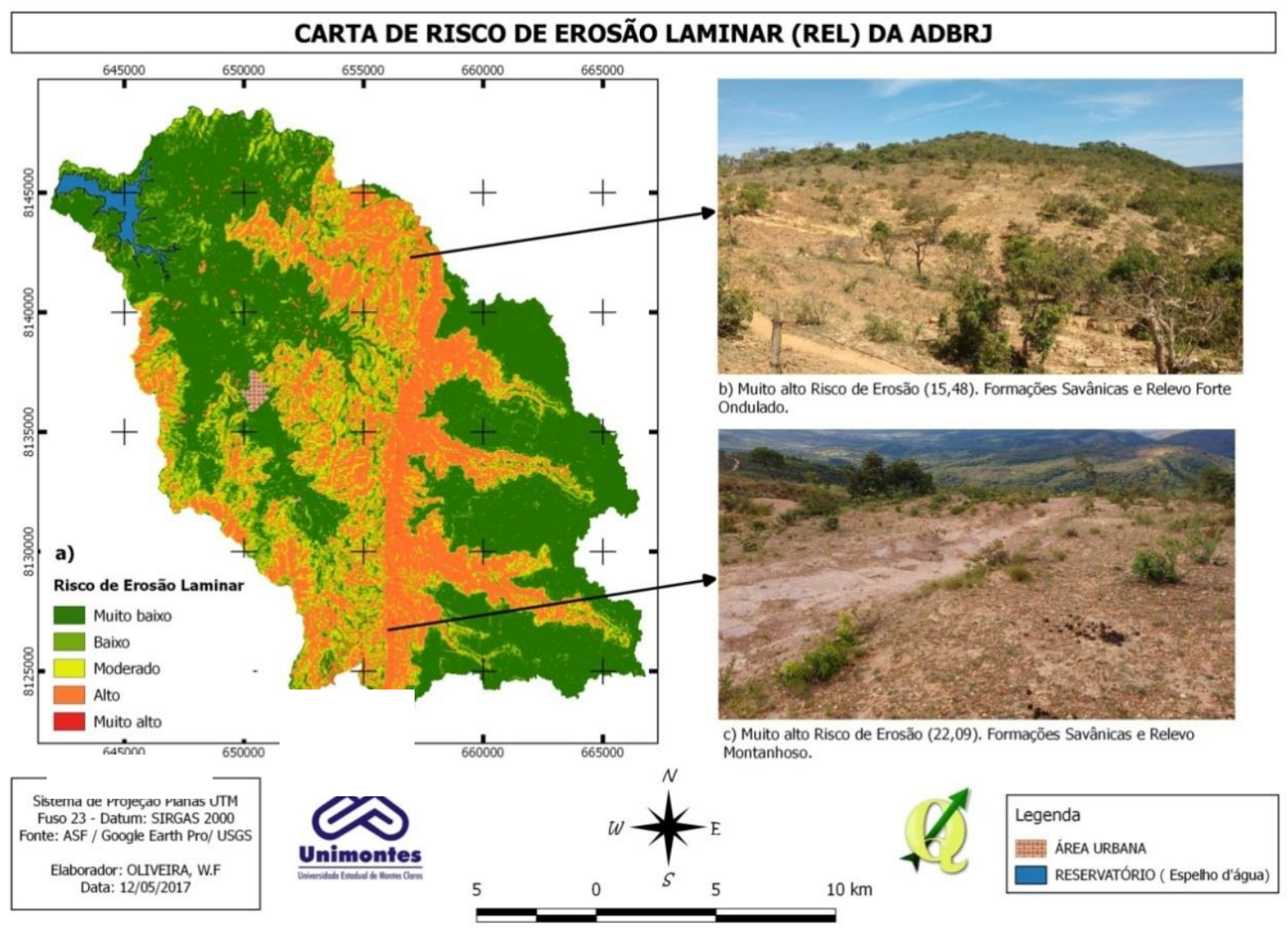

O dissecamento em tais áreas faz parte de um processo natural de evolução dos solos nas vertentes dessa região. Em alguns pontos, esse processo é intensificado por meio das atividades humanas, por exemplo: implantação de culturas agrícolas (perenes, anuais e pastagens) em detrimento da vegetação nativa e ausência das práticas conservacionistas do solo. Segundo Bigarella, Becker e Passos ( 1996), o solo quando submetido a esse processo, sujeito à interferência da ação humana no ambiente natural, gera absoluto desequilíbrio, tornando o ambiente instável do ponto de vista morfodinâmico, prevalecendo assim, as perdas de solo.

Acredita-se que, com a remoção do material da camada superficial (horizonte $\mathrm{O}$ e A) pela enxurrada, seguida pelo transporte, uma parte desse material será adicionado nas áreas de altitudes inferiores da bacia, na proporção das forças gravitacionais. Também, uma boa parte dos sedimentos transportados alcançará o reservatório da barragem, intensificando o assoreamento do mesmo. Tal processo é agravado no início do período chuvoso (outubro), quando na ocorrência de chuvas erosivas, as áreas de solos desnudados estão mais vulneráveis à erosão, elevando-se ainda mais a magnitude dos riscos.

As áreas aqui supracitadas (as áreas de alto e muito alto Risco de Erosão Laminar) estão desprovidas de práticas conservacionistas. Logo, são prioritárias nas políticas de recuperação de áreas degradas. Pouco contribui no processo de infiltração e armazenamento de água no solo.

$\begin{array}{llllll}\text { Caminhos de Geografia } & \text { Uberlândia - MG } & \text { v. 19, n. } 67 & \text { Set/2018 } & \text { p. 16-37 } & \text { Página } 33\end{array}$




\section{CONSIDERAÇÕES FINAIS}

As análises mostraram que as áreas de Pastagens avançam, por meio do desflorestamento, nas áreas de relevo mais acidentado da bacia e não foi encontrado adoção de práticas conservacionistas que mitigam o processo deletério da erosão hídrica nessa classe de uso da terra. Nessas áreas, as perdas de solos superam, em média, em até dez vezes ou mais a tolerância, desfavorecendo o processo de infiltração de água no solo e, consequentemente, o armazenamento e a produção de água. As consequências são diversas e a magnitude do risco eleva significativamente, de moderado para muito alto.

Por outro lado, as áreas de Silvicultura apresentaram-se práticas conservacionistas que proporcionam perdas de solos abaixo da tolerância para as condições atuais. Tal fator, certamente, favorece a infiltração e o armazenamento de água no solo, logo, a produção de água.

É evidente que o relevo é fator determinante no processo erosivo da ADBRJ. Sendo assim, o mesmo influi no processo de infiltração de água no solo, na velocidade e no volume do escoamento superficial (runoff). Em áreas com relevos acidentados e alta erodibilidade, eleva-se, naturalmente, o potencial erosivo. O risco de erosão laminar aumenta, significativamente, quando as práticas conservacionistas são desconsideradas.

Cerca de $52 \%$ da área total da bacia, encontra-se com Muito Baixo e Baixo risco de Risco de Erosão laminar. Entretanto, 32,91\% estão com Alto e Muito Alto Risco de Erosão Laminar. Em média, perdese 48,01 t.ha $^{-1}$.ano ${ }^{-1}$ na ADBRJ, valores que a classifica como magnitude Média em Perdas de Solos por Erosão Laminar.

Os maiores riscos de erosão ocorrem nos "Abruptos do Espinhaço" ou Escarpas Erosivas, os quais possuem as maiores declividades e solos altamente erodíveis. O dissecamento de tais vertentes faz parte de um processo natural de evolução dos solos. Em alguns pontos, esse processo é intensificado por meio das atividades humanas, por exemplo: implantação de culturas agrícolas em detrimento da vegetação nativa e ausência de práticas conservacionistas do solo e até mesmo práticas de incêndios clandestinos.

Dada a importância da ADBRJ, conforme apresentada neste trabalho e, diante da situação crítica de escassez hídrica nos últimos anos, faz necessário adotar algumas medidas que mitigam o processo erosivo e favoreçam 0 processo de infiltração da água no solo, 0 armazenamento e, consequentemente, a produção de água. Isso contribuirá na proteção e recuperação dos mananciais, gerando benefícios para a população dependente, direta ou indiretamente, deste precioso manancial.

Quanto às ferramentas geotecnológicas, foi possível elaborar o presente trabalho, meramente com ferramentas geotecnológicas livres, corroborando a importância de tais tecnologias na análise espacial geográfica.

\section{AGRADECIMENTOS}

Agradecemos a Fundação de Amparo à Pesquisa de Minas Gerais (FAPEMIG) pela bolsa de incentivo à pesquisa.

\section{REFERÊNCIAS}

ANA - Agência nacional de águas. Atlas Brasil. Brasília,DF: Agência Nacional de Águas, 2010. . Disponível em: <http://atlas.ana.gov.br/Atlas/forms/analise/Geral.aspx?est=8\&mapa=sist\#>. Acesso em: 12 ago. 2016.

ANA - Agência nacional de águas. Plano de recursos hídricos da bacia hidrográfica do rio Verde Grande. Brasília: CEDOC/Biblioteca, 2013.

ANA - Agência nacional de águas.. HidroWeb: Sistemas de Informações Hidrológicas. Disponível em: <http://www.snirh.gov.br/hidroweb/>. Acesso em: 12 abr. 2016.

ARRAES, C. L.; BUENO, C. R. P.; PISSARA, T. C. T. ESTIMATIVA DA ERODIBILIDADE DO SOLO PARA FINS CONSERVACIONISTAS NA MICROBACIA CÓRREGO DO TIJUCO, SP. Bioscience Journal, v. 26, n. 6, p. 849-857, 2010. Disponível em: <http://www.seer.ufu

.br/index.php/biosciencejournal/article/viewFile/7218/6604>. Acesso em:16 mar. 2017.

$\begin{array}{llllll}\text { Caminhos de Geografia } & \text { Uberlândia - MG } & \text { v. 19, n. 67 } & \text { Set/2018 } & \text { p. 16-37 } & \text { Página } 34\end{array}$


ASF - Alaska Satellite Facility. Vertex. Disponível em <https://vertex.daac.asf.alaska.edu>. Acesso em: 12 jun. 2017.

BARBOSA, A. F.; DE OLIVEIRA, E. F.; MIOTO, C. L.; PARANHOS FILHO, A. C. Aplicação da Equação Universal de Perda do Solo (USLE) em Softwares Livres e Gratuitos. Anuário do Instituto de Geociências, v. 38, n. 1, p. 170-179, 2015. Disponível em: <http://www.ppegeo.ig

c.usp.br/index.php/anigeo/article/view/5823>. Acesso em: 21 mai. 2017.

BERTONI, J.; LOMBARDI NETO, F. Erosão. In: Conservação do Solo. $9^{\circ}$ ed. São Paulo - SP: Icone Editora Ltda, 2014a. p. 68-93.

.Fotores que influem na erosão. In: Conservação do Solo. $9^{\circ}$ ed. São Paulo: Ícone Editora Ltda, 2014b. p. 45-67.

.Recursos naturais de caráter renovável. In: Conservação do Solo. $9^{\circ}$ ed. São Paulo - SP: Icone Editora Ltda, 2014c. p. 27-36.

BIGARELLA, J. J.; BECKER, R. D.; PASSOS, E. Estrutura e origem das paisagens tropicais e subtropicais. Florianópolis: Editora da UFSC, 1996.

BORGES, K. M. R. Avaliação da susceptibilidade erosiva da bacia do rio carinhanha ( $\mathbf{m g} / \mathbf{b a})$ por meio da eups: equação universal de perda de solos. 2009. Universidade de Brasília - UNB, 2009. Disponível em: <http://repositorio.unb.br/handle/10482/4117?mode=full>. Acesso em: 21 ago. 2016.

CECS. Centro de Estudos de Convivência com o Semiárido: Dados Meteorológicos. Disponível em: <http://www.cecs.unimontes.br/index.php/pt/dados-meteorologicos.html>. Acesso em: 18 abr. 2016.

CONGEDO, L. Semi-Automatic Classification Plugin Documentation. Disponível em: $<$ https://fromgistors.blogspot.com/p/semi-automatic-classification-plugin.html>. Acesso em: 9 nov. 2016.

COPASA - Companhia de Saneamento de Minas Gerais. Gerenciamento Geral de Serviços Técnicos e Correlatos para Implantação e Operação da Barragem de Regularização e Captação do Rio Juramento. Belo Horizonte:, 1983.

CORRÊA, E. A.; MORAES, I. C.; PINTO, S. dos A. F. ESTIMATIVA DA ERODIBILIDADE E TOLERÂNCIA DE PERDAS DE SOLO NA REGIÃO DO CENTRO LESTE PAULISTA. Geociências (São Paulo), v. 34, n. 4, p. 848-860, 2015. Disponível em: <www.revistageo

ciencias.com.br/34/volume34_4_files/34-4-artigo-08.pdf\%0A>. Acesso em: 18 abr. 2017.

COSTA, F. R. da ; ROCHA, M. M. GEOGRAFIA: CONCEITOS E PARADIGMAS - APONTAMENTOS PRELIMINARES. Rev. GEOMAE. Campo Mourão, PR, v.1, n.2, p.25-56, 2010. Disponível em: <http://www.fecilcam.br/revista/index.php/geomae/article/view/12>. Acesso em: 24 abr. 2017.

DA SILVA, A. M. Rainfall erosivity map for Brazil. Catena, v. 57, n. 3, p. 251-259, ago. 2004. Disponível em: <http://linkinghub.elsevier.com/retrieve/pii/S0341816203002595>. Acesso em: 28 dez. 2016.

DEMARCHI, J. C.; ZIMBACK, C. R. L. Mapeamento, erodibilidade e tolerância de perdas de solo na sub-bacia do Ribeirão das Perobas. Energia na Agricultura, v. 29, n. 2, p. 102-114, 2014. Disponível em: <http://revistas.fca.unesp.br/index.php/energia/article/view/841/973>. Acesso em:13 fev. 2017.

DENARDIN, J. E. Erodibilidade do solo estimada por meio de parâmetros fisicos e químicos. 1990. USP-ESALQ, 1990. Disponível em: <https://books.google.com.br/books?id=8z

7yZwEACAAJ>. Acesso em: 05 mai. 2017..

DESMET, P. J. .; GOVERS, G. A GIS procedure for automatically calculating the USLE LS factor on topographically complex landscape units. Journal of Soil and Water Conservation, v. 51, n. 5, p. 427-433, 1996. Disponível em: <https://www.researchgate.net/publication/233425

999_A_GIS_procedure_for_automatically_calculating_the_USLE_LS_factor_on_topographically_com plex_landscape_units>. Acesso em:10 jan. 2017. 
DEVATHA, C. P.; DESHPANDE, V.; RENUKAPRASAD, M. S. Estimation of Soil loss Using USLE Model for Kulhan Watershed, Chattisgarh- A Case Study. Aquatic Procedia, v. 4, p. 1429-1436, 2015. Disponível em: <http://linkinghub.elsevier.com/retrieve/pii/S2214241X150018

68>. Acesso em:10 ago. 2016.

EMBRAPA. Sistema brasileiro de classificação de solos. In: Sistema brasileiro de classificação de solos. 3a. ed. Brasília,DF: Embrapa Solos, 2013. p. 353.

FAO - Food and Agriculture Organization. Status of the World's Soil Resources - Main report. Rome: Food and Agriculture Organization of the United Nations, 2015. . Disponível em: $<$ http://www.fao.org/3/a-i5199e.pdf>. Acesso em: 11 ago. 2016.

FEAM - Fundação Estadual do Meio Ambiente. Banco de Solos de Minas Gerais. Disponível em <http://www.feam.br/noticias/1/949-mapas-de-solo-do-estado-de-minas-gerais>. Acesso em: 25 mai. 2017.

FOSTER, G. R.; MCCOOL, D. K.; RENARD, K. G.; MOLDENHAUER, W. C. Conversion of the universal soil loss equation to SI metric units. Journal of Soil and Water Conservation, v. 36, n. 6, p. 355-359, 1981. Disponível em: <http://www.jswconline.org/content/36/6/355.abstract>. Acesso em: 15 de fev. de 2017.

GALDINO, S. Estimativa da perda de terra sob pastagens cultivadas em solos arenosos da bacia hidrográfica do alto taquari - ms/mt. 2012. UNICAMP, 2012. Disponível em: <http://www.bibliotecadigital.unicamp.br/document/?code=000872767>. Acesso em: 24 abr. 2017.

GALDINO, S.; RISSO, A.; SORIANO, B. M. A.; VIEIRA, L. M.; PADOVANI, C. R.; POTT, A.; MELO, E. C.; JÚNIOR, N. de A. Perdas de Solo na Bacia do Alto TaquariCorumbá - MS, 2003. . Disponível em: <http://www.cpap.embrapa.br/publicacoes/online/BP44.pdf>. Acesso em: 15 de fev. de 2017.

GOOGLE EARTH PRO. Google Earth Pro versão 7.1. Disponível em

<https://www.google.com/earth/download/gep/agree.html>. Acesso em: 2 abr. 2017.

GRASS, D. T. Geographic Resources Analysis Support System (GRASS) Software, Version 7.0. Open Source Geospatial Foundation, 2015. . Disponível em: <http://grass.osgeo.org >. Acesso em:25 jan. 2017.

IBGE - Instituto Brasileiro de Geografia e Estatística. Malhas Digitais. Disponível em <https://downloads.ibge.gov.br/downloads_geociencias.htm>. Acesso em: 21 mai. 2017.

IBGE - Instituto Brasileiro de Geografia e Estatística. Manual técnico de pedologia. 3a. ed. Rio de Janeiro: Coordenação de Recursos Naturais e Estudos Ambientais, 2015.

LAGROTTI, C. A. A. Planejamento agroambiental do município de santo antônio do jardim - sp: estudo de caso na microbacia hidrográfica do córrego do jardim. 2000. UNIVERSIDADE ESTADUAL DE CAMPINAS - UNICAMP, 2000. Disponível em:

<http://www.bibliotecadigital.unicamp.br/document/?code=vtls000240611>. Acesso em: 18 abr. 2017.

MANNIGEL, A. R.; DE PASSOS E CARVALHO, M.; MORETI, D.; DA ROSA MEDEIROS, L. Fator erodibilidade e tolerância de perda dos solos do Estado de São Paulo. Acta Scientiarum.

Agronomy, v. 24, n. 5, p. 1335-1340, 2002. Disponível em: <http://eduem.uem.

br/ojs/index.php/ActaSciAgron/article/viewFile/2374/1787>. Acesso em: 18 abr. 2017.

MARTINS, S. G.; SILVA, M. L. N.; AVANZI, J. C.; CURI, N.; FONSECA, S. Fator cobertura e manejo do solo e perdas de solo e água em cultivo de eucalipto e em Mata Atlântica nos Tabuleiros Costeiros do estado do Espírito Santo. Scientia Forestalis, v. 38, n. 87, p. 517-526, 2010. Disponível em: $<$ http://www.ipef.br/publicacoes/scientia/nr87/cap19.pdf>. Acesso em:25 jan. 2017.

NEARING, M. . A single, continuous function for slope steepness influence on soil loss. Soil Science Society of America Journal, v. 61, n. 3, p. 917-919, 1997. Disponível em: $<$ https://dl.sciencesocieties.org/publications/sssaj/abstracts/61/3/SS0610030917?access=0\&view=pdf >. Acesso em:20 abr. 2017.

OLIVEIRA, W. F. de. Vulnerabilidade à erosão hídrica na área de drenagem da Barragem do Rio Juramento, MG. 2017. Unimontes, 2017.. 
PIRES, L. S.; SILVA, M. L. N.; CURI, N.; LEITE, F. P.; BRITO, L. de F. Erosão hídrica pós-plantio em florestas de eucalipto na região centro-leste de Minas Gerais. Pesquisa Agropecuária Brasileira, v. 41, n. 4, p. 687-695, 2006. Disponível em: <http://www.scielo.br/

pdf/\%0D/pab/v41n4/29818.pdf>. Acesso em: 05 mai. 2017.

PRUSKI, F. F. FATORES QUE INTERFEREM NA EROSÃO HÍDRICA DO SOLO. In: Conservação de solo e água: práticas mecâncias para o controle da erosão hídrica. $1^{\circ}$ ed. Viçosa-MG: UFV, 2006. p. 41-74.

ROSA, R. Análise Espacial em Geografia (Spatial Analysis in Geography). Revista da ANPEGE, v. 7, n. 1, p. 275-289, 2011. Disponível em: <http://anpege.org.br/revista/ojs2.4.6/index.php/anpege08/article/view/163 >. Acesso em: 21 mai. 2017.

SIAM. Sistema Integrado de Informação Ambiental. Disponível em: $<$ http://geosisemanet.meioambiente.mg.gov.br/gueb/geosisemanet/versao2>. Acesso em: 19 dez. 2016.

SILVA, M. A. da; SILVA, M. L. N.; CURI, N.; OLIVEIRA, A. H.; AVANZI, J. C.; NORTON, L. D. Water erosion risk prediction in eucalyptus plantations. Ciência e Agrotecnologia, v. 38, n. 2, p. 160-172, 2014. Disponível em: <http://www.scielo.br/scielo.php?script=sci_arttext\&pid=S1413-

70542014000200007>. Acesso em:24 abr. 2017.

UFV - Universidade Federal de Viçosa, CETEC - Centro Tecnológico de Minas Gerais, UFLA Universidade Federal de Lavras, FEAM - Fundação Estadual do Meio Ambiente. Mapas de Solos do Estado de Minas Gerais. Belo Horizonte: FEAM, 2010. Disponível em:

$<$ http://www.feam.br/noticias/1/949-mapas-de-solo-do-estado-de-minas-gerais>. Acesso em: 15 de mai. de 2016.

USDA - United States Department of Agriculture. Soil Texture Calculator. Disponível em: <https://www.nrcs.usda.gov/wps/portal/nrcs/detail/soils/survey/?cid=nrcs142p2_054167>. Acesso em: 21 nov. 2016.

National Soil Survey Handbook (NSSH): Soil Properties and Qualities -Soil Erodibility Factors, USLE, RUSLE2. Disponível em: <https://www.nrcs.usda.gov/wps/portal

/nrcs/detail/soils/ref/?cid=nrcs142p2054223\#25>. Acesso em: 15 de mar. de 2017.

USGS - United States Geological Survey. Earth Explorer. Disponível em $<$ https://earthexplorer.usgs.gov/>. Acesso em: 14 dez. 2016.

WISCHMEIER, W. H.; JOHNSON, C. B.; CROSS, B. V. A soil erodibility nomograph for farmland and construction sites. Journal of soil and water conservation, v. 26, p. 189-193, 1971.

WISCHMEIER, W. H.; SMITH, D. D. Predicting rainfall-erosion losses from cropland east of the rocky mountains-Guide for Selection of Practices for Soil and Water Conservation. p. 49, 1965. Disponível em: <https://naldc.nal.usda.gov/download/CAT87208342/PDF>. Acesso em: 31 mar. 2017.

WISCHMEIER, W. H.; SMITH, D. D. Predicting rainfall erosion losses: a guide to conservation planing. Washington: United States Departament of Agriculture, 1978.

Recebido em: 04/10/2017

Aceito para publicação em: 09/05/2018 